\title{
A Temporal Multiscale Analysis of the Waters off the East Coast of South Korea over the Past Four Decades
}

\author{
Young-Heon $\mathrm{Jo}^{1, *}$, Laurence C. Breaker ${ }^{2}$, Yu-Heng Tseng ${ }^{3}$, and Sang-Wook Yeh $^{4}$ \\ ${ }^{1}$ Department of Oceanography, Pusan National University, Busan, South Korea \\ ${ }^{2}$ Moss Landing Marine Laboratories, Moss Landing, CA \\ ${ }^{3}$ Climate and Global Dynamics Division, National Center for Atmospheric Research, Boulder, CO \\ ${ }^{4}$ Department of Marine Sciences and Convergent Technology, Hanyang University, ERICA, South Korea
}

Received 5 October 2012, accepted 31 December 2013

\begin{abstract}
We address the trends in water temperature variability to understand the local global warming effects through different time scales using daily sea surface temperature (SST) measurements from 1966 - 2004. The abrupt SST changes off of the east coast of Korea are related to similar changes observed in the North Pacific. Seasonal water temperatures have increased by at least a factor of two or more in winter than in summer. While SSTs on annual timescales have increased significantly, SSTs on interannual timescales have decreased slightly at all stations. The anomalies in SST decadal time scales reveal maxima in temperature occurring in the mid-to-late 1970's, circa 1990 and circa 2000. These maxima coincide with major peaks in the North Pacific Gyre Oscillation (NPGO) with a lag of 4 - 7 months. The most significant warming appears in the long-term SST trends at each station where it approaches $+0.05^{\circ} \mathrm{C} \mathrm{yr}^{-1}$. Overall, the SST off the east coast of Korea has increased at rates that are far greater than what is reported in many other marginal seas.
\end{abstract}

Key words: Global warming, Regional climate change, East/Japan Sea, Hilbert-Huang transform

Citation: Jo, Y. H., L. C. Breaker, Y. H. Tseng, and S. W. Yeh, 2014: A temporal multiscale analysis of the waters off the east coast of South Korea over the past four decades. Terr. Atmos. Ocean. Sci., 25, 415-434, doi: 10.3319/TAO.2013.12.31.01(Oc)

\section{INTRODUCTION}

The East Japan Sea (EJS) is a marginal sea located in the northwest Pacific surrounded by Korea, Japan and Russia (Fig. 1). It is connected to adjacent seas by five shallow straits: the Korea/Tsushima Strait to the East China Sea, the Kanmon Strait (also known as the Strait of Shimonoseki) and the Tsugaru Strait which connects to the Pacific Ocean, and the Soya Strait and the Tartar Strait which connect to the Okhotsk Sea. The mean EJS depth is $1753 \mathrm{~m}$ and the deepest sea floor is $3742 \mathrm{~m}$ below sea level. The sea has three major basins: the Yamato Basin in the southeast; the Japan Basin in the north; and the Ulleung Basin in the southwest. The Japan Basin is the deepest basin, while the Ulleung Basin is the shallowest. While the eastern continental shelves are relatively wide, the western continental shelves are narrow, particularly along the Korean coast, averaging about $30 \mathrm{~km}$ in width.

\footnotetext{
* Corresponding author

E-mail:joyoung@udel.edu
}

There are four surface current systems in the EJS, the Tsushima Warm Current (TWC), the East Korean Warm Current (EKWC), North Korean Cold Current (NKCC), and the Liman Current. The NKCC and the EKWC meet along the east coast of Korea (Fig. 1). The warm TWC saline water passes through the Korea Strait where the flow often bifurcates into western and eastern branches. According to Teague et al. (2002), the annual transport through the Korea/ Tsushima Strait is $2.7 \mathrm{~Sv}$. The eastern branch of the TWC flows northeastward along the Japanese coast (Yoon 1982) with some of its waters exiting through the Tsugaru Strait and the rest spreading further north into the NE Japan Basin. The western branch forms the EKWC and flows northward along the Korean coast (Seung 1992). The EKWC then turns eastward between $37^{\circ}$ and $39^{\circ} \mathrm{N}$, where it meets the NKCC (Seung and Kim 1989; Seung 1992). The NKCC originates in the Liman Current coming from the Tatar Strait and some of the denser water in the NKCC intrudes along the coast below the surface and thus, some subpolar water is transported south of the Korea Strait (Talley et al. 2006). 
The meridional location of the subpolar front varies significantly on a seasonal basis (Lee and Niiler 2005; Dorman et al. 2005) and the seasonal subpolar front separates the warm and the cold water EJS masses (Fig. 1). The numerical results also show a connection between the Kuroshio and the EJS through the TWC (Tseng et al. 2012). According to Tseng et al. the summer-averaged circulation represents the expected surface flow from May - August while the winter circulation corresponds to the period from November - February. The study also shows a direct link between the North Equatorial Current (NEC), the Kuroshio, the TWC and the coastal areas of interest.

Since the Korean Peninsula climate is influenced by the East Asian monsoon (Youn 2005), understanding relations between the SST and surface air temperature (SAT) is important. Chu et al. (1998) analyzed the temporal and spatial variabilities of SST and SAT in the EJS and found that there is a strong connection between certain SST and SAT empirical orthogonal function (EOF) modes based on the non-seasonal components. Youn (2005) reported that the air temperature spectrum around the Korean Peninsula showed that the interannual band of 1 - 7 years contains a dominant fraction of the total energy $(85 \%)$ followed by decadal variability (constituting $18 \%$ of the energy) at a mean period of 11.1 years.

Recently, Min and Kim (2006) reported that long-term coastal sea surface water warming trends along the eastern coast (over $0.02^{\circ} \mathrm{C} \mathrm{yr}^{-1}$ ) are higher than those in the western and southern regions. However, this study did not explain why the water in the EJS has warmed more than that of other seas around the Korean Peninsula. Yeh et al. (2010) also examined the SST variability characteristics in the EJS for the period 1891-2005 and showed that the low-frequency EJS SST variability is characterized by significant warming from the early 1940s to the late 1940s and from the mid1980s to the present. Yeh et al. (2010) suggested possible mechanisms for the low frequency EJS SST variability in conjunction with atmospheric variability, but, they did not look at more details on the EJS warming mechanism in interannual time scales.

There are eleven water masses in the study area according to Talley et al. (2006). They defined the water masses based on several formation processes including subduction and open ocean convection. A number of studies devoted to the EJS were reported in a special issue of the Journal of Oceanography (Vol. 19, No. 3, 2006). Only a small number of studies have reported on the impact of climate change in the EJS (e.g., Yasunari 1990; Kang and Bak 1993; Oh 1996; An and Park 1996; Minami et al. 1999; Hong et al. 2001; Kang et al. 2005; Park and Chu 2006). The long term trend in temperature in the EJS has been analyzed in Minami et al. (1999), where they found a long-term variation in potential temperature (PT) and dissolved oxygen (DO) in the Japan Sea Proper Water (JSPW). For instance, there are large increases in PT and DO as much as $0.16 \pm 0.09^{\circ} \mathrm{C}_{\text {century }}{ }^{-1}$ and $23.2 \pm 15.7 \mu \mathrm{mol}$ century $^{-1}$ at $800 \mathrm{~m}$ depth at the southeast EJS (station $\mathrm{P}$ at $37^{\circ} 43^{\prime} \mathrm{N}, 134^{\circ} 43^{\prime} \mathrm{E}$ ), respectively. However, that study did not explain how or why the water in the EJS has warmed.

This study used long time series daily SST at three locations along the east coast of Korea (Fig. 1) to analyze the temperature variability in these waters rather than those in

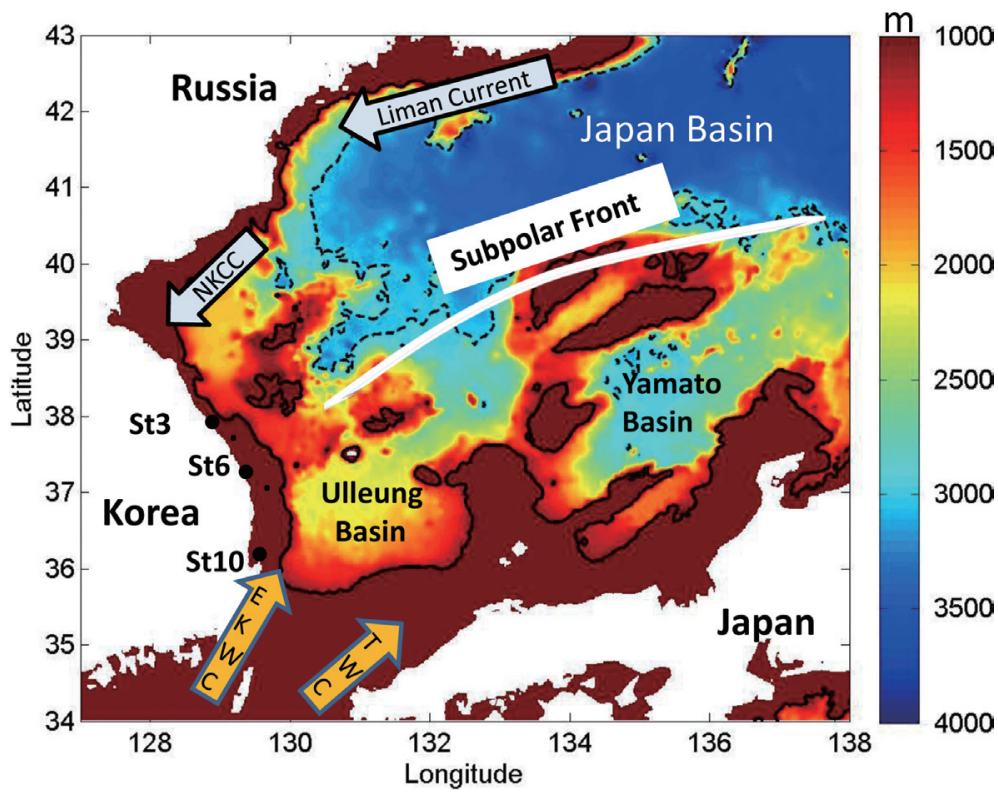

Fig. 1. Study area map. The three major basins are the Yamato Basin (YB), the Japan Basin (JB), and the Ulleung Basin (UB). The four main current systems are the Tsushima Warm Current (TWC), the East Korean Warm Current (EKWC), North Korean Cold Current (NKCC), and the Liman Current. The subpolar front location is adopted from Fig. 1 of Dorman et al. (2005). 
the whole EJS. These records span the same 39-year period from January 1, 1966 through December 31 2004. To examine these records we employed several analysis methods including cumulative sums (Hawkins and Olwell 1998) for detecting abrupt SST changes, the method of expanding means (Breaker and Flora 2009), Ensemble Empirical Mode Decomposition (Wu and Huang 2009) for decomposing the SST into different timescales and LOESS smoothing (Cleveland 1979). We analyze the variability of the waters off the east coast of South Korea and discuss the question of how these waters have warmed over the past four decades.

We organized this study based on timescales, starting with the shortest time-scales, i.e., regime shifts (section 4), followed by seasonal warming (section 5), the annual cycle (section 6), interannual variability (section 7), decadal timescales (section 8), and, finally, long-term trends (section 9).

\section{DATA AND DATA PROCESSING}

Since 1910 the Korean National Fisheries Research and Development Institute (NFRDI) has collected oceanographic and meteorological data at coastal stations along the Korean Peninsula (http://www.nfrda.re.kr). The observation site network includes 40 coastal stations. The observation periods were interrupted by the Korean War (1950 - 1953). Although some observation stations were restored right after the war, it took a few more years for many stations to resume oceanographic and meteorological data collection. Since 1981 the Korea Oceanographic Data Centre (KODC) has archived data from most of these coastal monitoring stations.

The stations used in this study along the coast of Korea cover the southwestern region of the EJS, from $35^{\circ}-38^{\circ} \mathrm{N}$, and from $129^{\circ}-132^{\circ} \mathrm{E}$. We selected three coastal stations for this study: station 3 (Juminjin) at $37.8^{\circ} \mathrm{N}, 128.8^{\circ} \mathrm{E}$, station 6 (Jukbyeon) at $37^{\circ} \mathrm{N}, 129.5^{\circ} \mathrm{E}$, and station 10 (Janggigap) at $36^{\circ} \mathrm{N}, 129.7^{\circ} \mathrm{E}$ (Fig. 1). The locations of these stations are approximately $66 \mathrm{~km}$ apart and not influenced by freshwater discharge from rivers. With respect to data quality, there are $1716(12 \%), 358(2.5 \%), 268(1.9 \%)$ missing observations out of a total of 14245 days (including leap days) at stations 3, 6, and 10, respectively. The measurement accuracy is approximately $\pm 0.1^{\circ} \mathrm{C}$ according to the NFRDI data description. Because most of the missing values were randomly spaced at scattered times, linear interpolation was applied to fill in the gaps without compromising the overall data quality. Outliers are defined as those data points that exceed neighboring values by $5^{\circ} \mathrm{C}$ or greater and were thus removed using a median filter. The $5^{\circ} \mathrm{C}$ threshold was applied to sea surface temperature anomalies (SSTA) for the median filter because the upper and lower outliers are about $\pm 5^{\circ} \mathrm{C}$ (Fig. 2b). The median filter is a nonlinear digital filtering technique, often used to remove noise. In the median filtering operation, the values in the neighborhood window are sorted according to magnitude and the middle value (the median) becomes the output value (Pratt 1978).

After removing the leap days for computational convenience, each record contains 14235 daily observations. For certain applications the daily SST observations are averaged weekly or monthly. The SST mean, standard deviation (STD), maximum and minimum are shown in Table 1. The variances are relatively small before and after applying the median filter.

Figure 2a shows the daily SST. The figure reveals strong seasonal variations in SST with the highest temperature in August and September, and the lowest in February and March. Based on the locations of stations 3,6, and 10 , we expected that significant differences between them might exist because of their exposures to the NKCC and the EKWC coastal currents are different. In order to examine the data in greater detail, SSTA histograms were created for each station. The kurtosis and skewness are also given for each station and can be found in the caption in Fig. 2b. Most of the observations show relatively high kurtosis, which tends to have a distinct peak near the mean. At the same time all of the SST data show negative skewness, indicating a lack of symmetry about the mean and the stronger influence of warming processes.

To examine the inter-station differences, we calculated cross-correlations between the three stations with and without pre-whitening. Pre-whitening removes the serial correlation from each time series. Long-range persistence or correlation is strong in these records because of the annual cycle. Pre-whitening effectively removes its influence, thus serving as a high-pass filter. The cross-correlation between stations 3 and 10 is shown in Fig. 3. As expected, without pre-whitening, annual cycle dominance is obvious in the upper curve (black). Of greater interest in our view is the cross-correlation obtained after pre-whitening (shown by the blue line). A small but statistically significant peak occurs at zero lag, suggesting that signal propagation between stations $3-10$ is unimportant within the sampling time scale. Because the peak occurs at zero lag, we can infer that propagating disturbances, at least those occurring at the scales we can resolve with daily sampling, are not a significant factor. However, there is information contained in the residuals at much longer time scales, as will be examined later in this study. Similar results were obtained for the cross-correlations between stations 3 and 6 , and 6 and 10 .

\section{METHODS}

\subsection{Cumulative Sums}

We have employed the method of cumulative sums to detect change points that may correspond to abrupt changes such as regime shifts. This method has been shown to be particularly sensitive to detecting change points such as regime shifts in coastal observations of SST (Breaker 2007; Breaker and Flora 2009). Cumulative Sums (CUSUMs) represent 
the running total of the deviations of the first $n$ observations from a mean based on the same interval (Page 1954; Wetheril and Brown 1991; Hawkins and Olwell 1998; Breaker 2007). The Cumulative Sums (CS) can be expressed as,

$$
\mathrm{CS}=\sum_{t=1}^{n}\left(x_{t}-\bar{x}\right)
$$

where $x_{t}$ represents the $n^{\text {th }}$ observation, $\bar{x}$ is the mean of $x_{t}$

(a) Daily SST for 39 years at Station 3

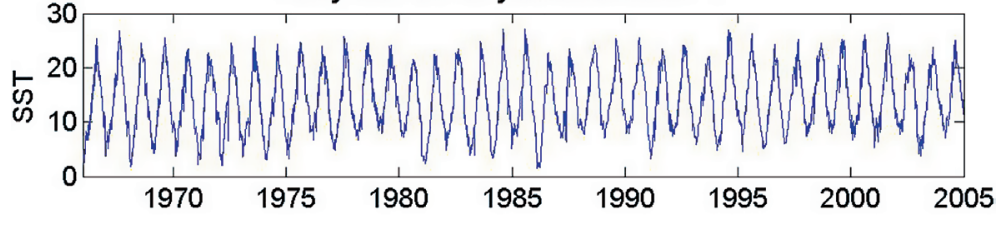

Daily SST for 39 years at Station 6
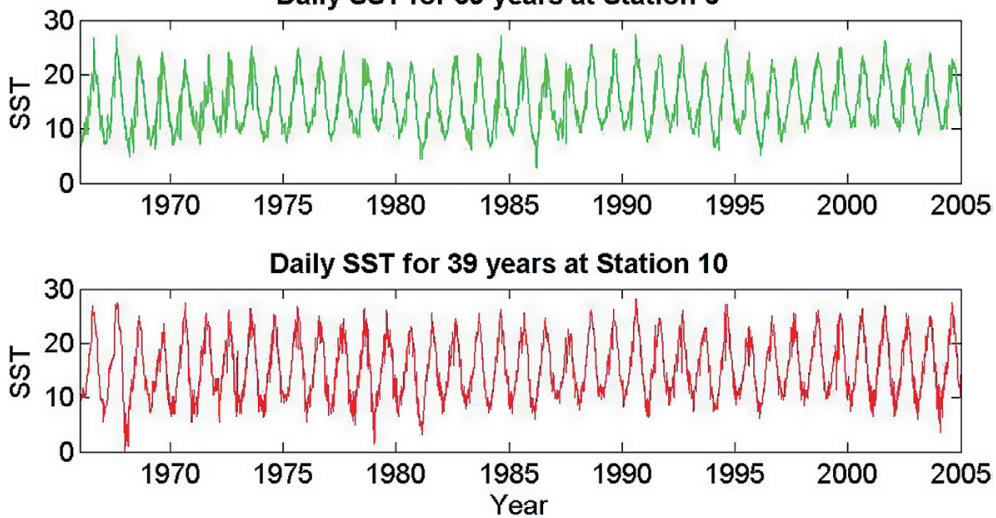

(b)
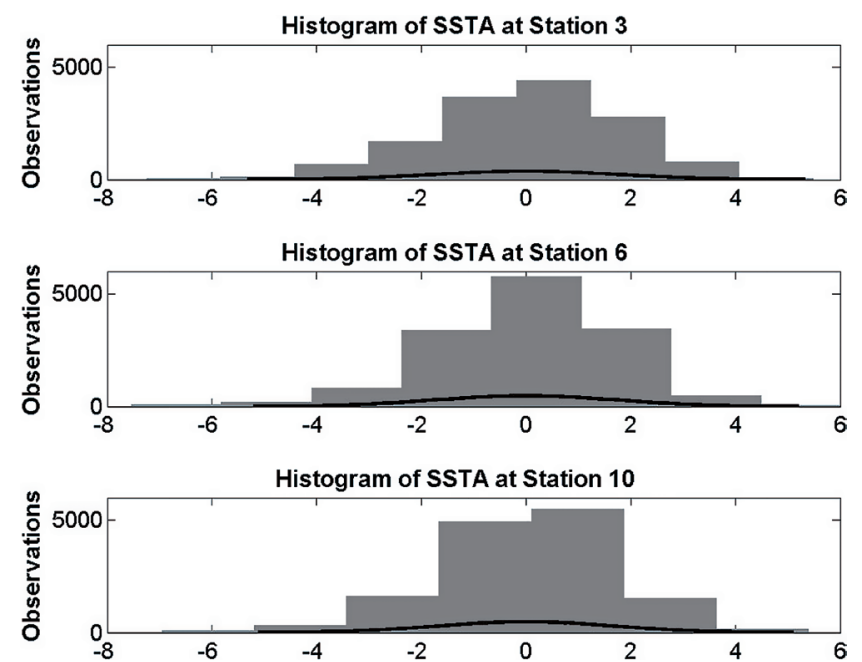

Fig. 2. Daily sea surface temperature from 1966 - 2004 for stations 3, 6, and 10, respectively (a), and histogram of sea surface temperature anomaly at three stations (b). The black curve represents a normal distribution. The Kurtosis and skewness are 3.22 and -0.41 for station $3,4.5$, and -0.62 for station 6 , and 4.38 and -0.55 for station 10 , respectively.

Table 1. Statistics obtained from the daily raw SST data.

\begin{tabular}{ccccc}
\hline Station/Statistic & Mean $\mathbf{T}\left({ }^{\circ} \mathbf{C}\right)$ & $\mathbf{S T D}\left({ }^{\circ} \mathbf{C}\right)$ & Maximum Temperature $\left({ }^{\circ} \mathbf{C}\right)$ & Minimum Temperature $\left({ }^{\circ} \mathbf{C}\right)$ \\
\hline 3 & 14.09 & 5.77 & 27.10 & 1.50 \\
6 & 14.95 & 4.72 & 27.50 & 2.80 \\
10 & 15.58 & 5.34 & 28.10 & 1.20 \\
\hline
\end{tabular}




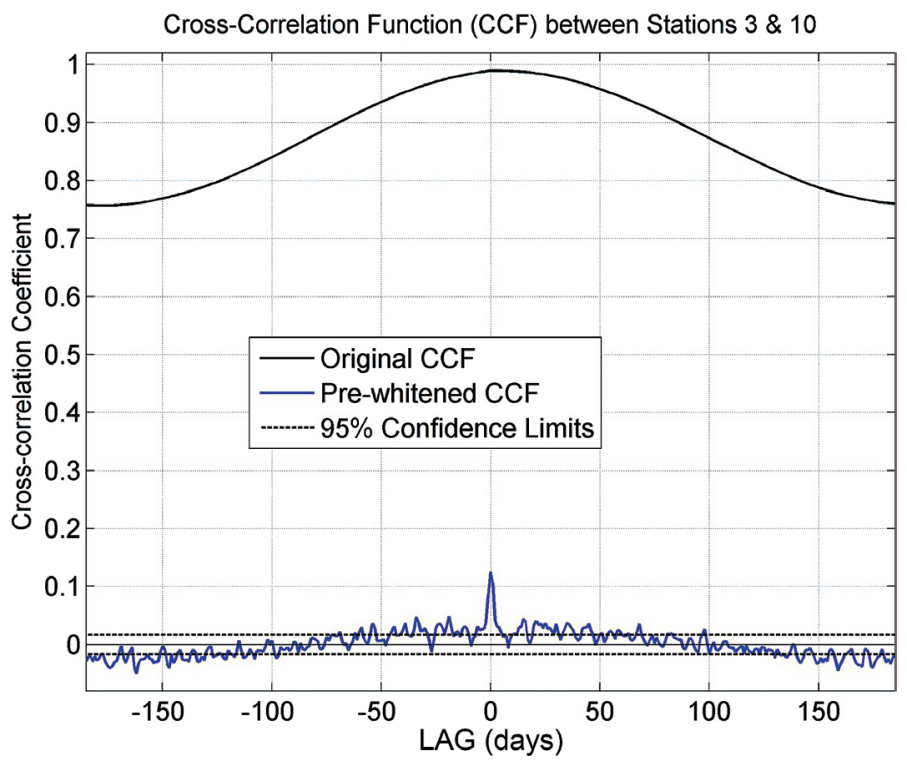

Fig. 3. Cross-Correlation Function (CCF) between stations 3 and 10.

from $t=1$ to $n$, and CS is plotted versus time to produce the so-called CUSUM chart. Abrupt changes in the slope of the CUSUM often reflect change points, which, in our case, could indicate regime shifts. Coastal temperatures may increase or decrease, depending on the location as a result of regime change. These events have time scales on the order of six months and may have a long-term impact on the mean state of the ocean.

\subsection{Ensemble Empirical Mode Decomposition}

In order to examine to what extent the different SST variability time scales contribute to warming (or cooling), we have decomposed the SSTs at each location into independent modes using Ensemble Empirical Mode Decomposition (EEMD). The mathematical details of this procedure are given in the Appendix. Each of these modes represents a certain range of zero-crossing periods or frequencies and accounts for a certain fraction of the total variance. The variance by mode number is shown at the top panel of each figure. The modes are identified as $\mathrm{C} 1$ through $\mathrm{C} 9$, with the last mode referred to as the residual. The residual contains information on any long-term trends in the data (Huang et al. 1998). In many cases, individual modes or selected mode groupings may provide physically meaningful interpretations. In such cases we may be able to relate a particular mode or mode grouping to a known physical process. The results of the EEMD decompositions are introduced here and shown in Figs. 4, 5, and 6. All modes (shown in Figs. 4, 5, and 6) at stations 3,6, and 10 were statistically significant at the $95 \%$ confidence level based on a testing method proposed by $\mathrm{Wu}$ and Huang (2005) against the white noise null hypothesis, except for C9 at St. 10 (Fig. 6).
In each case, the variance is greatest for mode $\mathrm{C} 4$, or modes $\mathrm{C} 3$ and $\mathrm{C} 4$, and represents the variance associated with the annual cycle. Modes $\mathrm{C} 1$ and $\mathrm{C} 2$ show high frequency variability in most cases, which is not of interest to us in this study. Although seasonal timescales are of interest and their zero-crossing periods fall within modes $\mathrm{C} 2$ and $\mathrm{C} 3$, they are addressed outside the EEMD framework so that we could examine the different seasons separately. Modes $\mathrm{C} 3$ and $\mathrm{C} 4$ generally capture the variability associated with the annual cycle, modes C5 and C6 contain variability that occurs on interannual time scales, modes $\mathrm{C} 7$ and $\mathrm{C} 8$ contain variability generally associated with interdecadal time scales, and mode C9 and the residual contain information generally related to long-term trends. The contributions of each mode are discussed in the corresponding sections of the text.

\section{THE 1976 - 1977 REGIME SHIFT}

The 1976 - 1977 regime shift was a major event that affected most climatic and ecosystem indicators in the North Pacific basin and has been documented extensively. Breaker (2007) and Breaker and Flora (2009) used daily and weekly SSTs from single locations off the coasts of California and Hawaii to examine the 1976 - 1977 regime shift and other regime shifts in detail. CUSUMs were calculated from the daily and weekly time series to detect the regional imprint of these events. Breaker and Flora (2009) were able to detect and localize the 1976 - 1977 event off southern California and Hawaii and found that SSTs increased by up to $+1^{\circ} \mathrm{C}$ off Southern California, and by up to $+0.5^{\circ} \mathrm{C}$ off Oahu, Hawaii.

Because the 1976 - 1977 regime shift was reported to be basin-wide (e.g., Bakun 2004), we examined the daily observations from stations 3,6 , and 10 to determine if it 


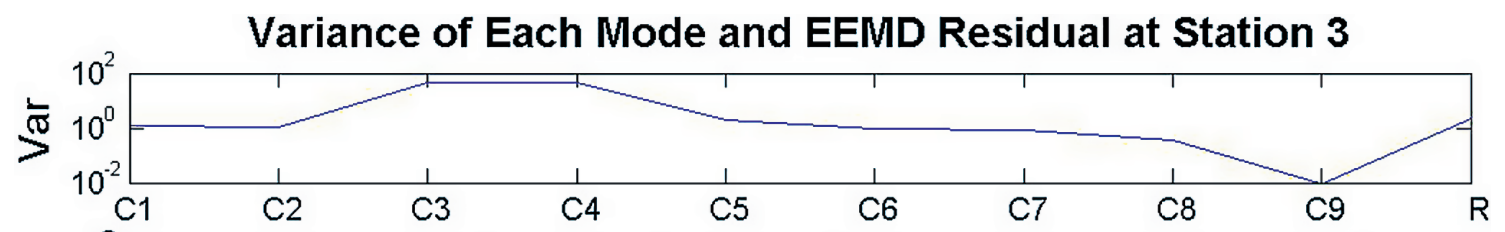

0
0 $\int_{-2}^{2}$

$\begin{array}{ll}\mathbf{U} & 0 \\ \mathbf{U} & 0\end{array}$

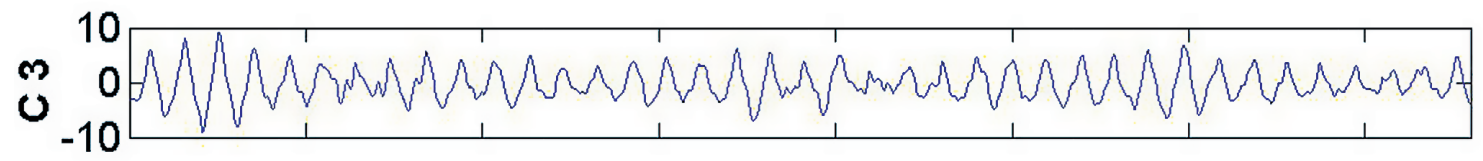

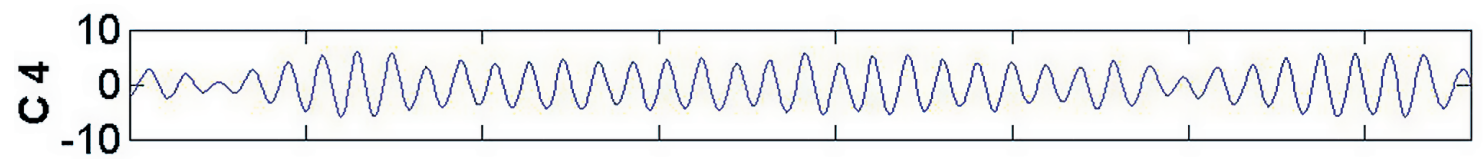
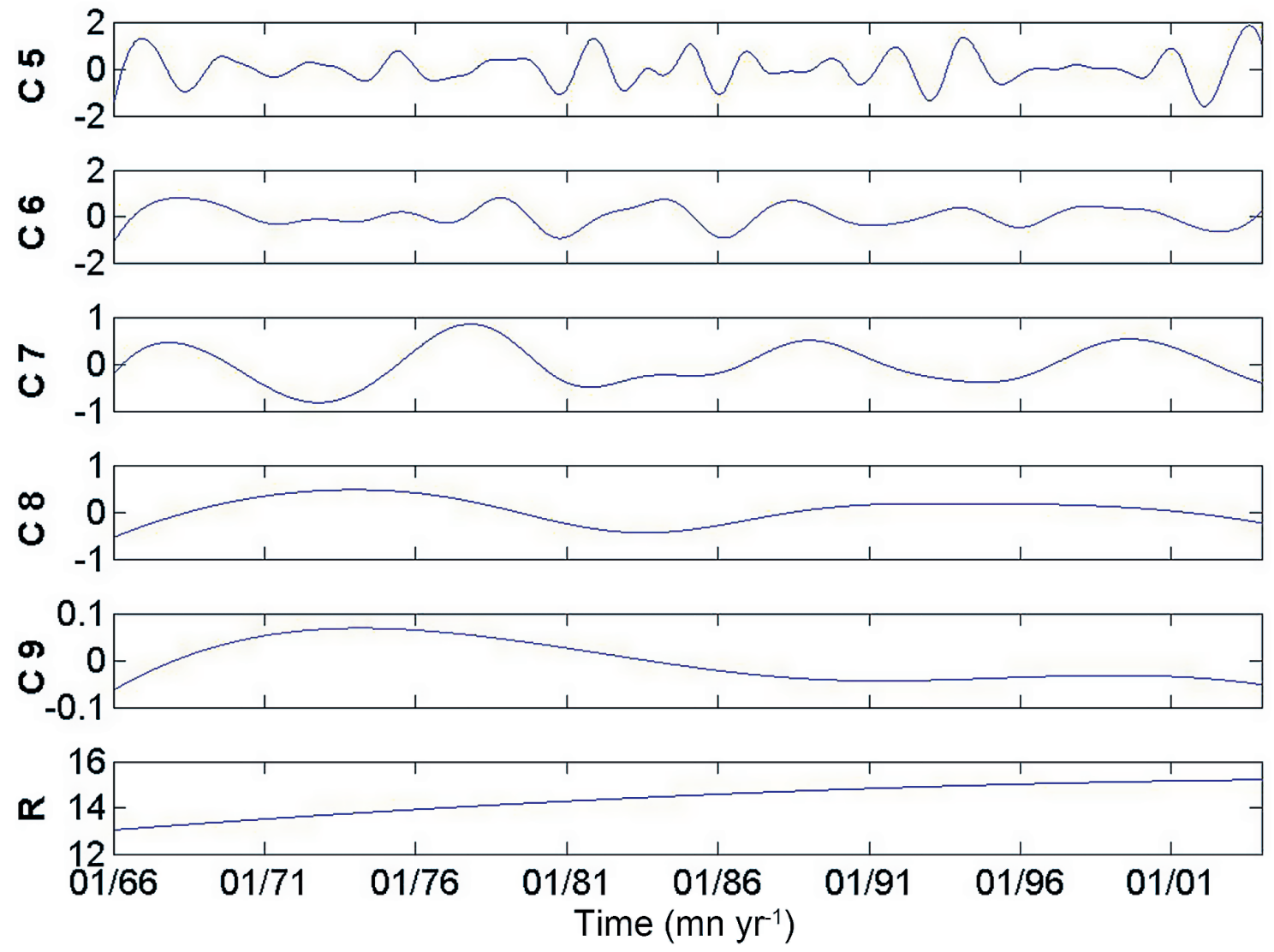

Fig. 4. Variances of each EEMD mode on the first panel and EEMD modes C1 - C9 and EEMD residual from the second to the eleventh panel for station 3 . All modes were statistically significant at $95 \%$ confidence level. 

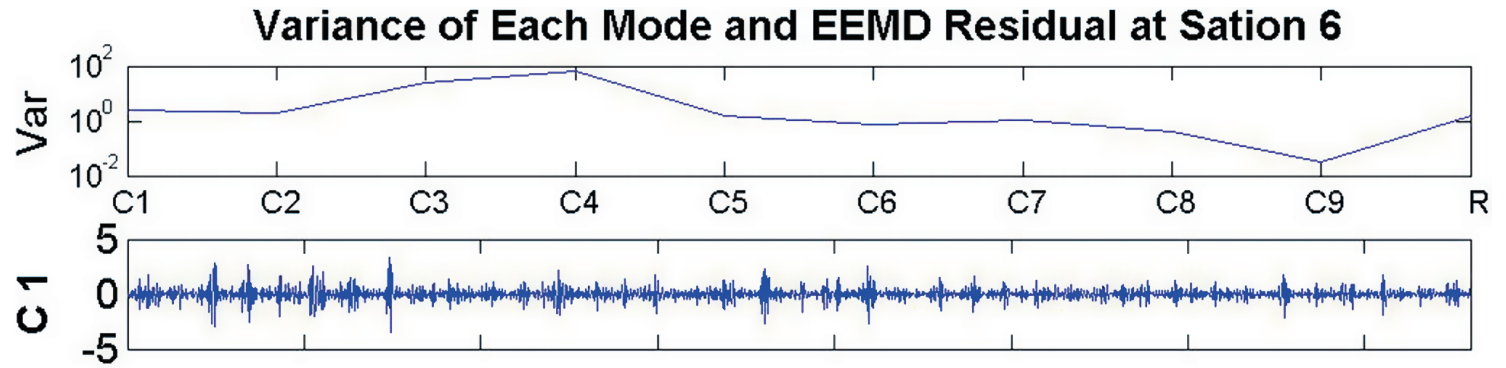

$\begin{array}{ll}\text { N } & 5 \\ 0 & 0 \\ -5\end{array}$

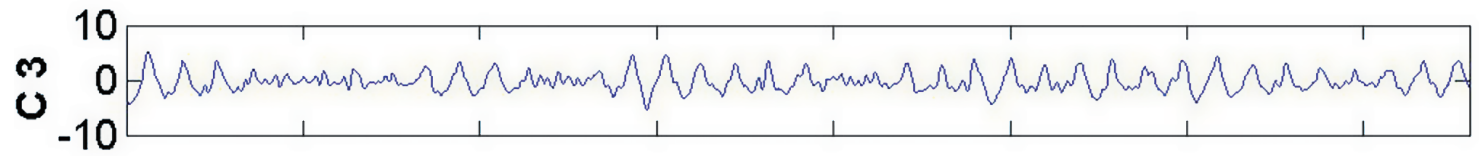

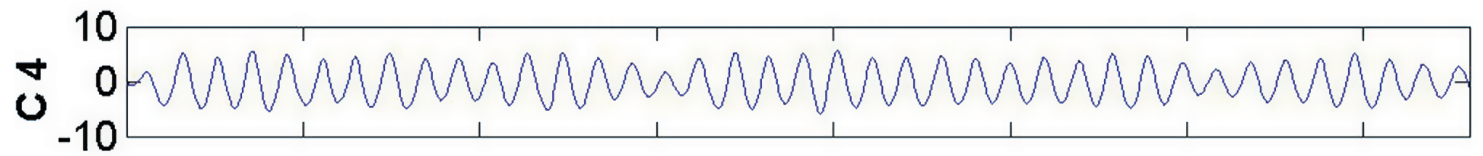
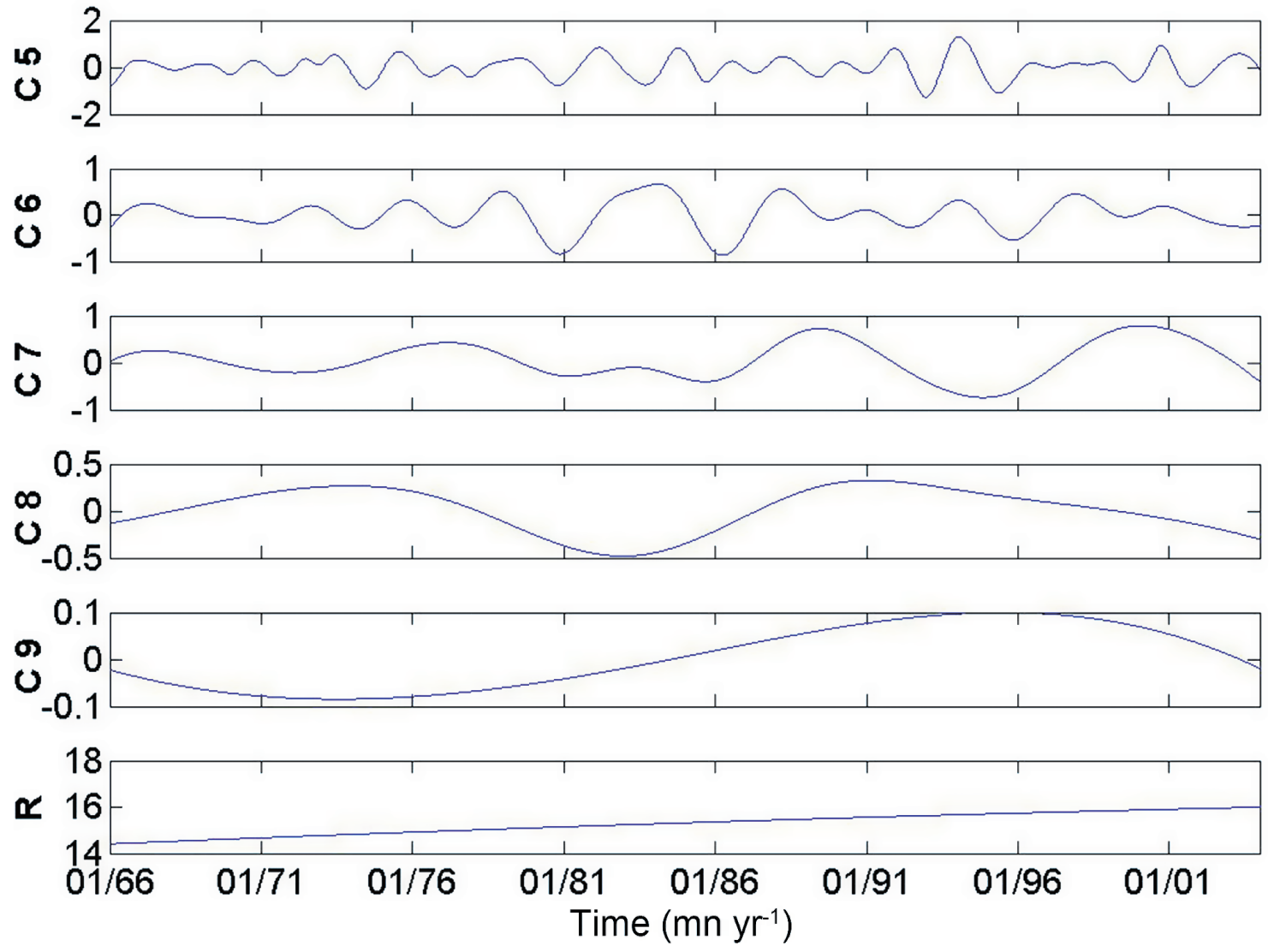

Fig. 5. Variances of each EEMD mode on the first panel and EEMD modes C1 - C9 and EEMD residual from the second to the eleventh panel for station 6. All modes were statistically significant at $95 \%$ confidence level. 

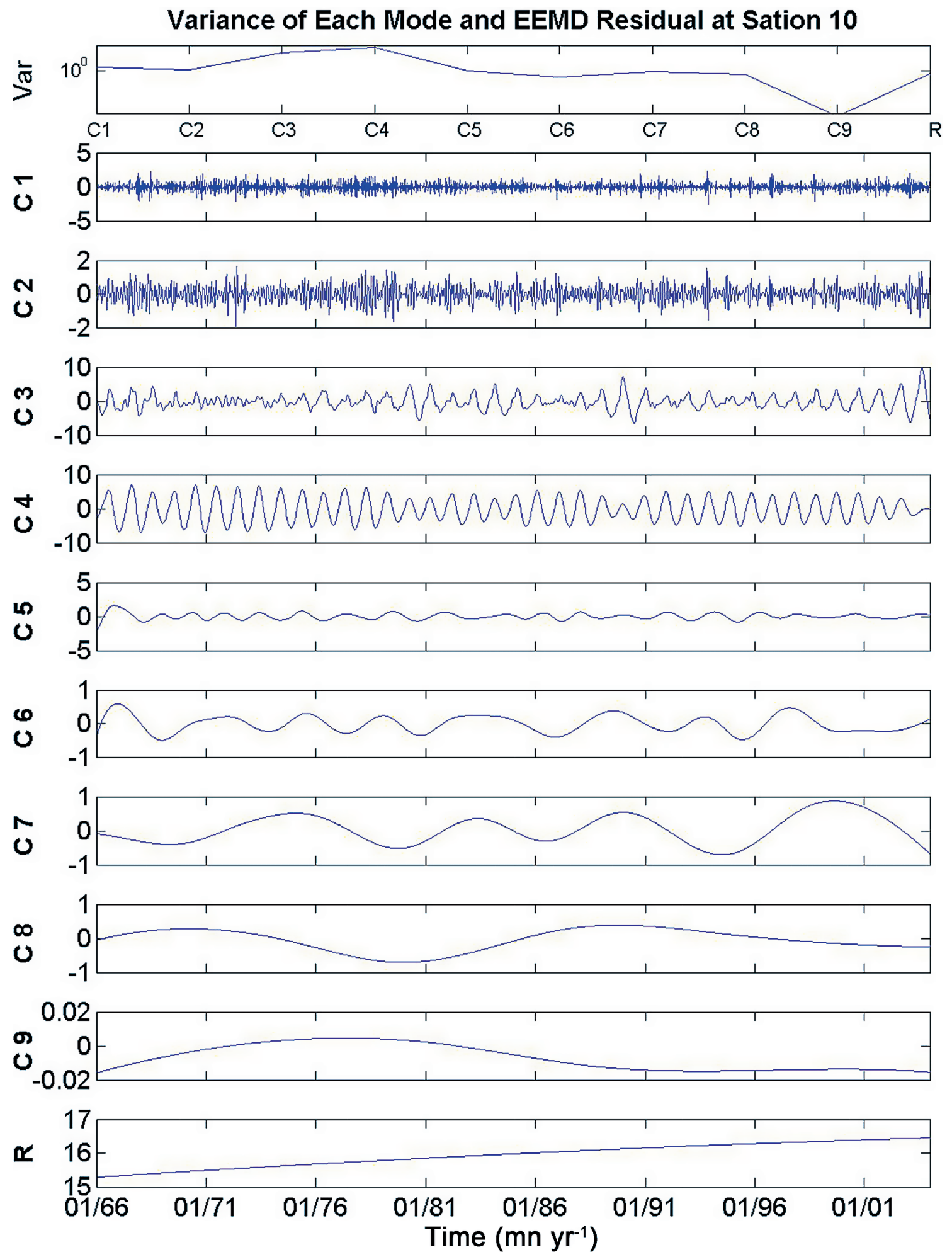

Fig. 6. Variances of each EEMD mode on the first panel and EEMD modes C1 - C9 and EEMD residual from the second to the eleventh panel for station 10. All modes were statistically significant at $95 \%$ confidence, except mode C9. 
could be detected off the coast of South Korea. CUSUMs were calculated for all 3 stations and the results are shown in Fig. 7, together with those for Scripps Pier off southern California and Koko Head off Oahu, Hawaii (Figs. 7a and b). The CUSUMs for stations 3, 6, and 10 are shown in blue, green, and red, respectively. The slopes in all three figures (Figs. 7a - c) are all negative, implying that a decrease in temperature has occurred. All three locations off the coast of South Korea exhibit similar signals around the time of the shift with a lag of $1-2$ months compared to the signals for Scripps Pier and Koko Head. The concurrent SST signals at three locations around the time of the regime shift of interest suggest the only significant events of a similar nature that occur in the overall CUSUM plots for several years leading up to and following this period. Thus, we can state that the turning point patterns shown with arrows in Fig. 7 found in SST off South Korea are consistent with the turning point patterns found by Breaker and Flora (2009) for approximately the same time period at different locations in the North Pacific for an event that has been reported to be basin-wide in extent. If we compare the approximate midpoints of this event (approximately half-way between the turning points that tend to occur at the beginning and end of each event) in the CUSUMs at Scripps Pier ( 1976.9) and off the coast of South Korea $(\sim 1977.1)$, it appears that its arrival off the coast of South Korea was delayed by at least a month or two, suggesting that this event, if these patterns do in fact represent the same event, did not occur simultaneously throughout the North Pacific basin. The long-term SSTA variability associated with decadal time scales is discussed in section 8 .

To estimate the impact of the 1976 - 1977 regime shift we also show the expanding mean diagram (Breaker and Flora 2009) for station 6 (Fig. 7d). Because all three stations exhibit similar behaviors, we chose to show only that of station 6 for two reasons. First, it was a slightly better station to interpret the differences between the backward and forward directions from $t_{0}$ than for the other two stations. Second, the differences in each case were generally similar and so there was no compelling reason to show the results for all three stations. Starting at the approximate mid-point of the regime shift, the mean temperatures are calculated moving away from the mid-point in the forward and reverse directions, one day at a time, until the mean values extend out to several years. The curves tend to stabilize after roughly the first year with significant differences often found. In this case, after year one, we observe slight decreases in temperature at each station although it is most apparent at station 10 (not shown). At station 3, by the end of year two the temperatures were almost the same and thus show little

CUSUMs for 1976 - 1977 Regime Shift off Southern California, Hawaii, and South Korea

(a)

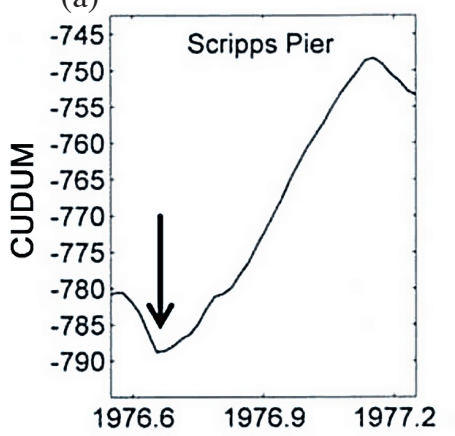

(b)

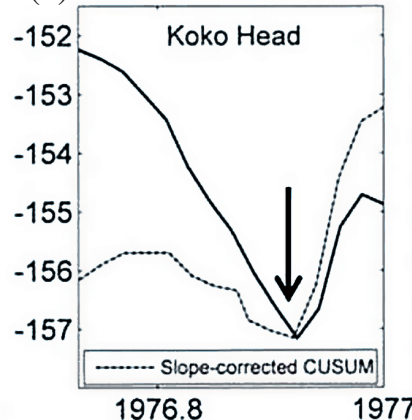

(c)

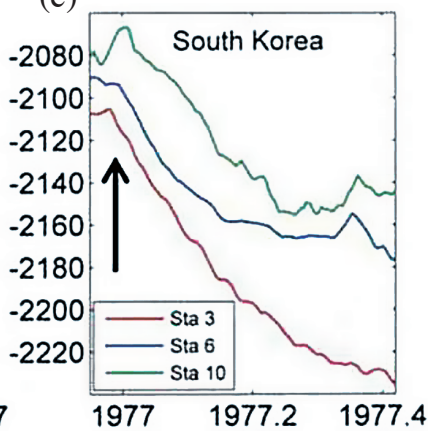

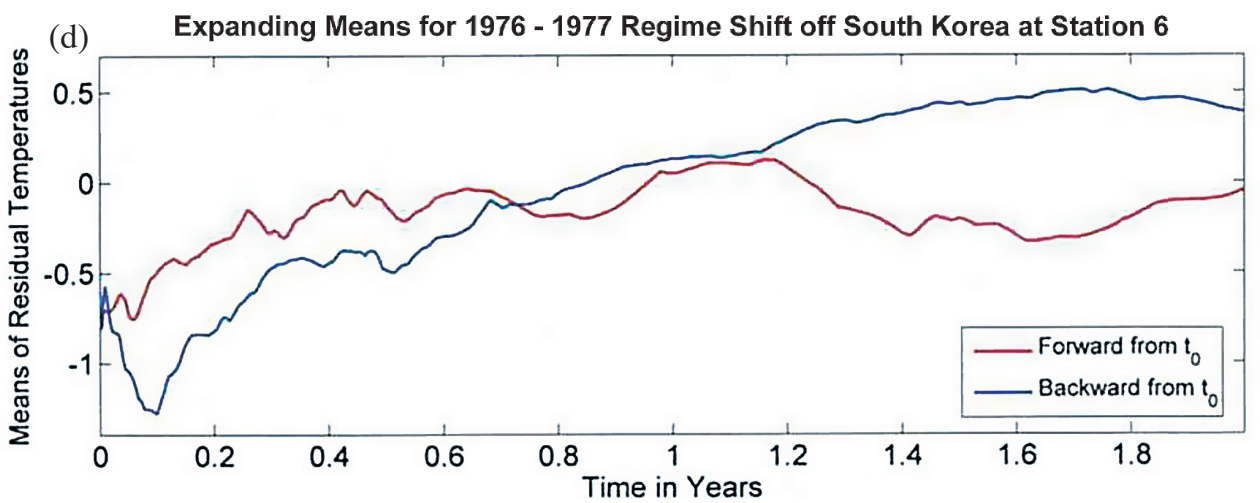

Fig. 7. Cumulative sums (CUSUMs) for Scripps Pier, off southern California (a), and Koko Head, off Oahu, Hawaii (b), and all 3 stations (c). Expanding means for 1976 - 1977 regime shift off S. Korea for stations 3, 6, and 10 (d), respectively. 
long-term impact. The changes seem to reflect decreases in temperature, which is consistent with the CUSUMs results. We find it interesting that although the long-term trends at each station are strongly positive over the entire record, the changes that occurred during the 1976 - 1977 regime shift served to decrease temperatures (Fig. 7c).

The EJS response to the regime shift has been investigated in previous studies with respect to marine ecosystem and fishery resources. For instance, Zhang et al. (2000) analyzed biological changes in the ecosystems off Korea where in response to the 1976 regime shift, Zhang et al. (2007) also analyzed the effects on the structure and function of the southwestern EJS ecosystem after the 1988/89 regime shift. Kidokoro et al. (2010) analyzed the migration of Japanese common squid due to the climate regime shift before and after 1989 and Tian et al. (2013) reported that the squid abundance trends were forced largely by latitudinal environmental factor differences in response to the climate regime shift. The results of these studies, in our view, add credence to the results we presented on coastal SSTs.

\section{WARMING ON SEASONAL TIMESCALES}

In order to examine possible seasonal influences on the warming process we calculated the monthly means for each station and then created separate sequences for each month, producing 12 time series, each containing 39 monthly values. Although the monthly values are widely scattered, we fitted linear trends to each time series using the least squares method. To provide a measure of the goodness-of-fit to the linear trends, the standard deviations for each month and station were also calculated. The standard deviation ranges from about $0.78^{\circ}-2.21^{\circ} \mathrm{C}$.

The slopes are extracted from each linear trend and the smoothed version of the monthly slopes is plotted in Fig. 8 . The smoothed versions of the monthly slopes are plotted in Fig. 8. The slopes are from $+0.071^{\circ} \mathrm{C} \mathrm{yr}^{-1}$ in February to $+0.016^{\circ} \mathrm{C} \mathrm{yr}^{-1}$ in August for station 3, from $+0.065^{\circ}{\mathrm{C} \mathrm{yr}^{-1}}^{-1}$ in May to $+0.045^{\circ} \mathrm{C} \mathrm{yr}^{-1}$ in October for station 6, and from $+0.072^{\circ} \mathrm{C} \mathrm{yr}^{-1}$ in December to $+0.012^{\circ} \mathrm{C} \mathrm{yr}^{-1}$ in August for station 10 . These rates of increasing temperature are relatively large, implying long-term increases of up to $\sim 6.5^{\circ} \mathrm{C}$ during the winter season and up to $\sim 2.3^{\circ} \mathrm{C}$ during the summer season over 100 years. The P-values (confidence level) for the corresponding regression coefficients are less than 0.05 , except for January, April, July and August, whose Pvalues are $0.06,0.1,0.7$, and 0.8 , respectively. These warming rates along the east coast of Korea may be influenced by the atmosphere and/or ocean through teleconnections (Belkin 2009). We will discuss this topic further after examining other warming sources presented in the final section.

A small warming trend occurs in the summer despite the large heat content, particularly for stations 3 and 10, station 6 located in the subpolar front and influenced by both the NKCC and the EKWC (Fig. 1), which may help explain the different seasonal warming rates in this case.

For comparison, Balling et al. (1988) estimated winter and summer warming rates on the global scale over the period from 1946 - 1995. They found that warming is greatest at higher latitudes in the Northern Hemisphere, particularly in the low-sun season rather than in the high-sun season. Specifically, they found a warming rate of $+0.08^{\circ} \mathrm{C}_{\text {decade }}{ }^{-1}$ for the winter season and $+0.05^{\circ} \mathrm{C}$ decade $^{-1}$ for the summer season. Furthermore, Yeh and Kim (2010) reported that the changes in the atmospheric circulation over the North Pacific play a role in increasing the SST in the East Asian marginal sea through air-sea exchange modification. On the regional scale, Belkin (2009) reported changes in SST in four different regional seas between 1982 and 2006. He found warming rates for the Baltic Sea of $+0.054^{\circ} \mathrm{C} \mathrm{yr}^{-1}$, for the North Sea, $+0.0524^{\circ} \mathrm{C} \mathrm{yr}^{-1}$, for the East China Sea, $+0.0488^{\circ} \mathrm{C} \mathrm{yr}^{-1}$ and for the EJS, $+0.0436^{\circ} \mathrm{C} \mathrm{yr}^{-1}$. During the same period the SST warming rate for our study was approximately $+0.048^{\circ} \mathrm{C} \mathrm{yr}^{-1}$. A few studies showed that northern hemisphere dynamics are strongest in winter and have a greater effect on the regional warming difference (Yeh and Kim 2010). Our finding seems to be consistent with this.

\section{THE ANNUAL CYCLE}

In order to examine the annual cycle we first calculated the Mean Annual Cycle (MAC) by calculating the mean value for each day of the year taken over the number of years in the record shown with mode C4, Figs. 4, 5, and 6 for three

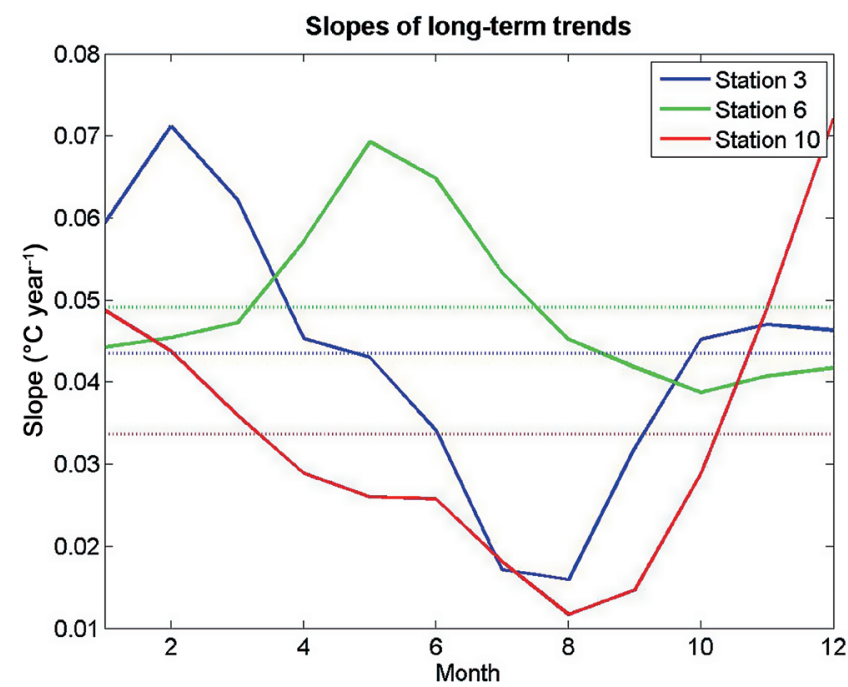

Fig. 8. The slopes of the long-term linear trends are shown for each month for stations 3, 6, and 10: station 3 (blue), station 6 (green), and station 10 (red). To reduce the month-to-month variability, the monthly values have been smoothed slightly. The horizontal dashed lines indicate the global mean values in each case, showing that, overall, the warming is greatest at station $6\left(\sim+0.049^{\circ} \mathrm{C} \mathrm{yr}^{-1}\right)$, followed by station 3 $\left(\sim+0.044^{\circ} \mathrm{C} \mathrm{yr}^{-1}\right)$, and then station $10\left(\sim+0.039^{\circ} \mathrm{C} \mathrm{yr}^{-1}\right)$. 
stations. The MACs for stations 3 (blue), 6 (green), and 10 (red) are shown in Fig. 9a. Slightly smoothed versions are also shown. A period during July is highlighted in black and shown in expanded form in Fig. 9b. The slightly reduced temperatures compared to the smoothed versions are due to upwelling which is known to occur along the coast due to the seasonal southeast winds which become upwellingfavorable at this time of year (Lee 1978; Lee 1983).

The annual cycle is the dominant feature in the record at each station. Compared to the variance in the entire record, the variance in the MAC is $90.5 \%$ of the total variance at station 3,86.7\% of the total variance at station 6 , and $89.8 \%$ of the total variance at station 10 (Fig. 9). Their mean and standard deviations can be found in the caption in Fig. 9. In order to determine the contribution of different time scales to warming and cooling, we have drawn upon the EEMD analyses shown in Figs. 4, 5, and 6. The EEMD analyses results form the basis for Figs. 10a and b, which will be referred to frequently. First the linear slopes were fitted to the data for each station as mean values and are shown as horizontal dashed lines. The solid lines show the linear slopes when selected modes were withheld in order to estimate the contribution of each mode to the warming process. Departures from the original slope indicate warming when they lie below the horizontal line and cooling when they lie above. The approximate confidence limits associated with the slopes for each station are also included in Fig. 10a. Following Emery and Thomson (1997), we calculated the decorrelation time-scales from the autocorrelation functions (ACFs) and then estimated the degrees-of-freedom, $\mathrm{N}^{*}=$ $N / \tau$, where $N$ is the original number of observations and $\tau$ is the de-correlation timescale, taken as the time required for the ACF to decay to $1 / \mathrm{e}(0.368)$. We then applied a standard t-test (e.g., Huntsberger 1965) to determine the $95 \%$ confidence limits. Because $\mathrm{N}^{*}$ is far smaller than $\mathrm{N}$ the associated confidence limits are relatively wide and overlap extensively for all three stations, indicating that the differences in the slopes are often not statistically significant. However, none of the lower confidence limits cross zero, which indicates that all of the slopes are significantly greater than zero, at the $95 \%$ confidence level.

The $\mathrm{C} 3$ and $\mathrm{C} 4$ modes correspond to the annual cycle and show that they do contribute to higher SSTs (Fig. 10a). Specifically, as shown in Fig. 10a, these modes contribute to significant warming at stations $3\left(+0.047^{\circ} \mathrm{C} \mathrm{yr}^{-1}\right), 6$ $\left(+0.05^{\circ} \mathrm{C} \mathrm{yr}^{-1}\right)$, and $10\left(+0.034^{\circ} \mathrm{C} \mathrm{yr}^{-1}\right)$. The warming is similar at each location, which is consistent with the possibility for an atmospheric contribution to the warming process on this time scale. Recall that the seasonal warming trends shown in Fig. 8 (section 5) indicate that this warming is greatest during the winter.

Due to the dominance of the annual cycle we removed the MAC from the data in order to examine interannual, decadal and longer changes in temperature with greater clarity.
This is the procedure most often used to correct data from the MAC influence. For station 3 the variance after removing the MAC is reduced from 33.0 to 2.9 (a $91 \%$ reduction), for station 6, from 21.8 to 2.54 (an $88.3 \%$ reduction), and for station 10, from 27.9 to 2.39 (a $91.4 \%$ reduction) (also see Table 2).

\section{INFLUENCE OF EL NIÑO AND LA NINA EPI- SODES}

We examine the SST variability in interannual time scales. The El Niño-Southern Oscillation (ENSO) is the dominant climate variability mode on the interannual time scale. ENSO events include both El Niño and La Nina. According to Hong et al. (2001) SSTAs in the EJS are closely related to ENSO events. Their results indicated (1) that the summer in the year (year 0) in which El Niño events develop tends to be colder than in the year prior to the event (year -1 ), whereas the winter tends to be warmer and (2) during La Nina events these patterns are reversed. In order to identify the timing and magnitude of ENSO events we employed the Multivariate ENSO Index (MEI) (http://www.cdc.noaa. gov/people/klaus.wolter/MEI/), where strongly positive values that persist for up to a year or longer represent El Niño events, and negative values that persist for up to a year or longer represent La Nina events (Fig. 11a). The MEI shows that La Ninas tended to dominate prior to the mid-1970s, at about the time of the 1976 - 1977 regime shift, whereas El Niños tend to dominate following this period.

We examined the SSTAs at all three stations to see if we could detect patterns similar to those observed by Hong et al. (2001) along the coast of Korea. The results are shown in Fig. 11. We observe decreases in SSTA of almost $2^{\circ} \mathrm{C}$, up to a year prior to the 1982 - 1983, 1986 - 1987, and 1997 - 1998 El Niño events, as indicated by the vertical yellow dashed lines. Similarly, we examined the relationship between composite SSTA and ENSO events and observed decreases in SSTA of almost $1.5^{\circ}, 1^{\circ}$, and $2^{\circ} \mathrm{C}$, up to a year prior to the 1982 - 1983, 1986 - 1987, and 1997 - 1998 El Niño events (not shown). The correlation between composite SSTA and MEI is 0.1 at $97 \%$ significance level.

We see similar decreases in SSTA during the 1992 to 1993 El Niño but it is not clear from the MEI when this event actually started. We do not see any clear relationship between the SSTAs and La Nina events. Overall, we do not observe the same relationships as those observed by Hong et al. (2001).

We conducted a cross-correlation analysis between the MEI and the SSTAs at each station. ${ }^{1}$ The results indicate weak but consistent correlations between the MEI and all

1 Both pre-whitened and non-pre-whitened cross-correlations were calculated and the results were generally similar for both. 
Mean Annual Cycles of SST at Stations 3 (blue), 6 (green), and 10 (red)

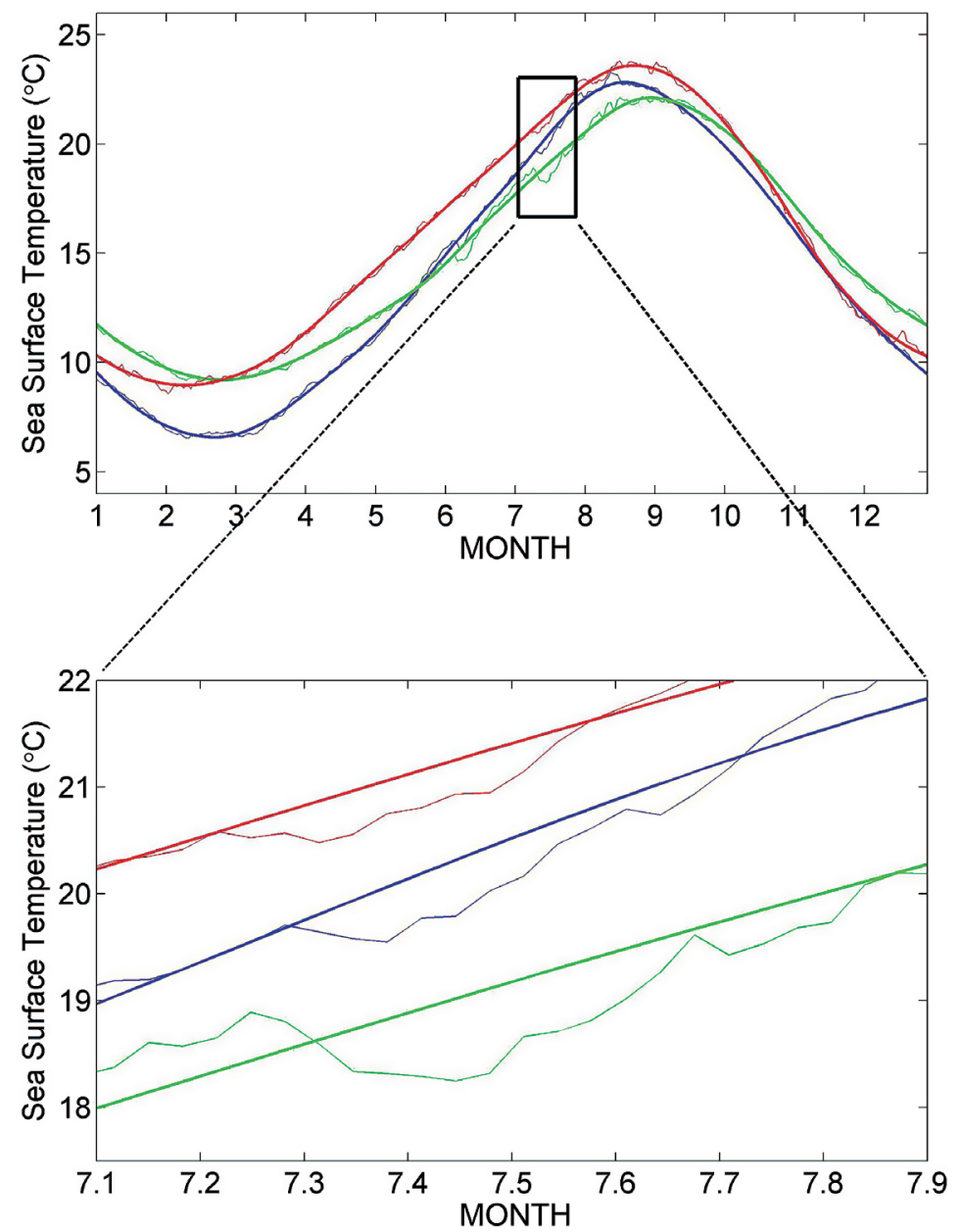

Fig. 9. Mean Annual Cycles (MACs) for stations 3, (blue), 6 (green), and 10 (red) are shown in the upper panel. The mean (and standard deviation) for stations 3,6 , and 10 are $14.09^{\circ}\left(5.77^{\circ} \mathrm{C}\right), 14.95^{\circ}\left(4.72^{\circ} \mathrm{C}\right)$, and $15.58^{\circ}\left(5.34^{\circ} \mathrm{C}\right)$, respectively. Smoothed versions of the MACs are shown as well by the darker lines. The black box highlights the period during the summer when coastal upwelling occurs along the coast of South Korea. The lower panel shows this region in greater detail.

(a)

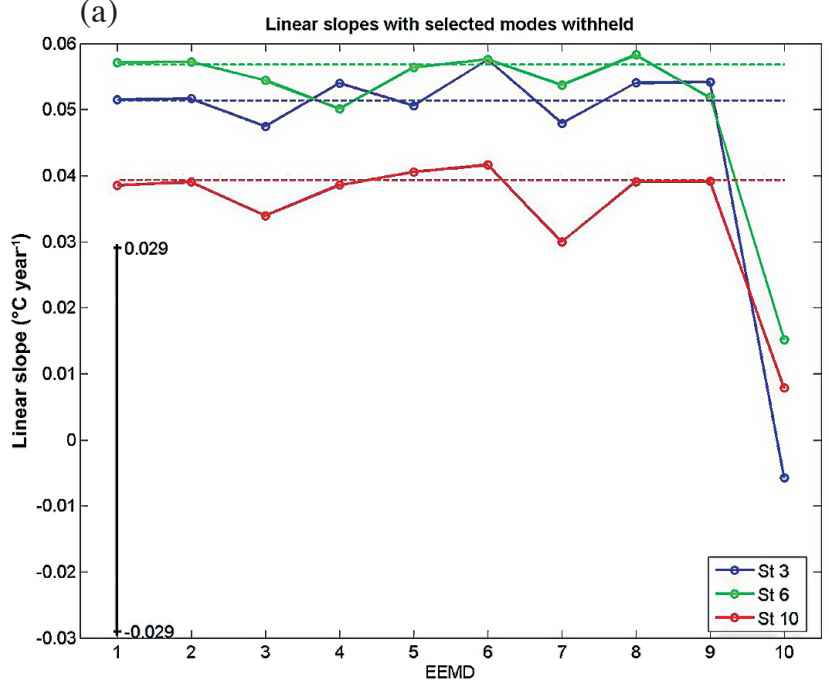

(b)

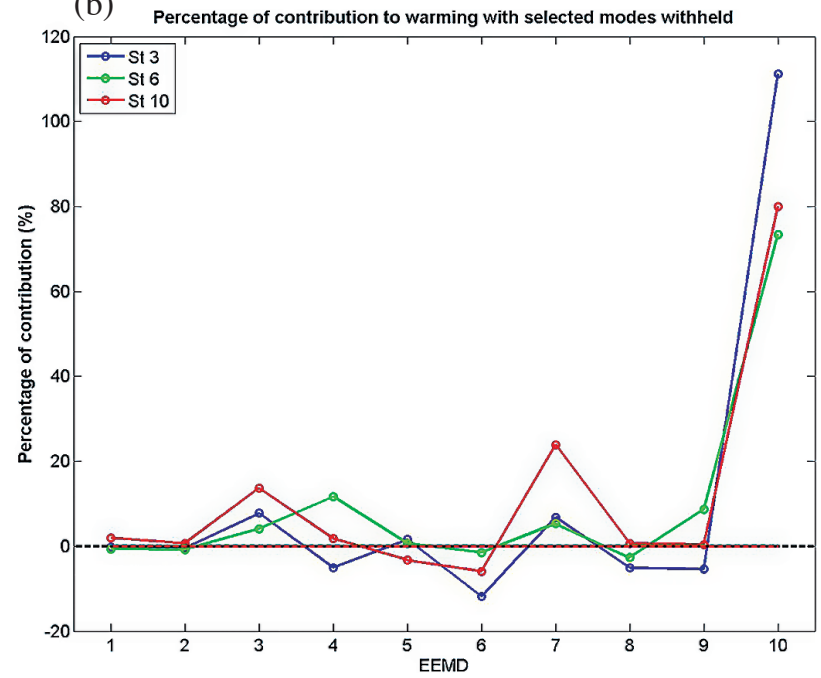

Fig. 10. Linear slopes with selected EEMD mode withheld (a) and percentage of contribution to warming with selected EEMD modes withheld (b). 
Table 2. Variance of each EEMD mode for sea surface temperature with and without the MAC.

\begin{tabular}{l|ccc|ccc}
\hline & \multicolumn{3}{|c|}{ SST with MAC } & \multicolumn{3}{c}{ SST without MAC } \\
\cline { 2 - 8 } & St 3 & St 6 & St 10 & St 3 & St 6 & St 10 \\
\hline C1 & 1.1707 & 2.3758 & 1.9930 & 0.2248 & 0.3181 & 0.3567 \\
C2 & 1.1231 & 1.9159 & 1.1705 & 0.2156 & 0.2565 & 0.2095 \\
C3 & 43.1473 & 23.5084 & 26.2220 & 8.2845 & 3.1479 & 4.6934 \\
C4 & 48.1524 & 66.7353 & 67.0066 & 9.2456 & 8.9361 & 11.9932 \\
C5 & 2.0300 & 1.5582 & 1.1119 & 0.3898 & 0.2086 & 0.1990 \\
\hline C6 & 0.9989 & 0.7844 & 0.3414 & 0.1918 & 0.1050 & 0.0611 \\
C7 & 0.8814 & 1.1068 & 0.9420 & 0.1692 & 0.1482 & 0.1686 \\
\hline C8 & 0.3563 & 0.4033 & 0.5653 & 0.0684 & 0.0540 & 0.1012 \\
C9 & 0.0090 & 0.0331 & 0.0003 & 0.0017 & 0.0044 & 0.0001 \\
\hline R & 2.1308 & 1.5789 & 0.6469 & 0.4091 & 0.2114 & 0.1158 \\
\hline
\end{tabular}

(a) Multivariate ENSO Index (MEI)

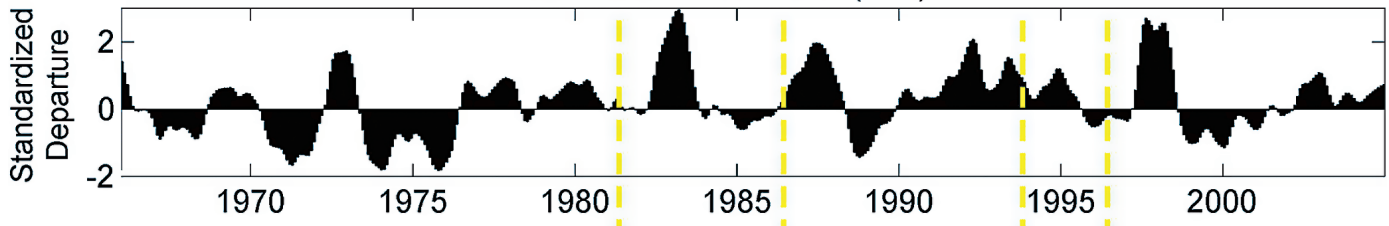

(b)

Station 3

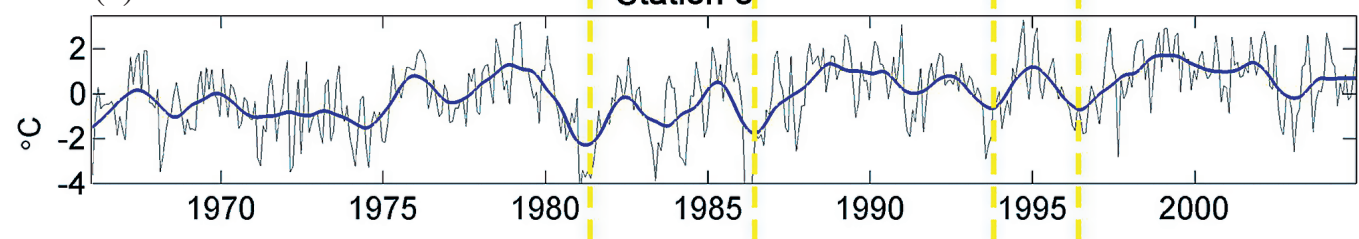

(c)

Station 6

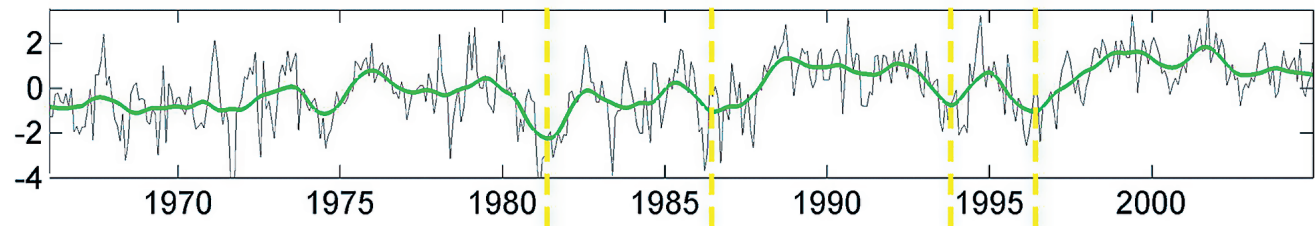

(d)

Station 10

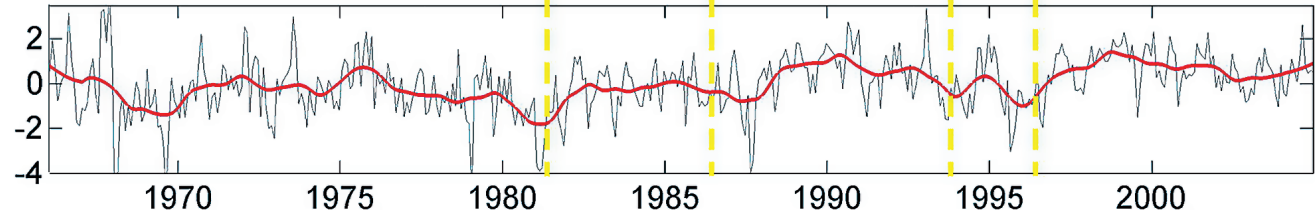

Fig. 11. Time series comparison between Multivariate ENSO Index (MEI) (a) and SSTA for stations 3 (b), 6 (c), and 10 (d), respectively.

three stations, with maximum negative correlations occurring at lags of -4 months and slightly larger positive correlations occurring at lags of about $11-13$ months, with the MEI leading in these cases. In most cases the correlations were not statistically significant at the $95 \%$ level of confidence. However, at station 10, the largest maximum correlation occurred at a lag of approximately one year, with station 10 leading the MEI, generally consistent with our previous observations from Fig. 11. Specifically, correlations between MEI and SSTA at stations 3, 6, and 10 
are 0.06 at 3 months lag at $85 \%$ confidence level, 0.06 at 4 months lag at $88 \%$ confidence level, and 0.125 at 4 months lag at $95 \%$ confidence level.

We conclude that the variability associated with the SSTAs on interannual time scales is not completely independent of that associated with ENSO events, and although the relationships are weak, they may still be meaningful.

From our EEMD decomposition the zero-crossing periods associated with modes $\mathrm{C} 5$ and $\mathrm{C} 6$ correspond to interannual time scales and so include ENSO-related variability. In order to examine whether ENSO events contribute to long-term warming or cooling, as with the lower modes, we computed the trends with and without the ENSO-related modes (Figs. 10a and b). The ENSO events appear to contribute to a slight cooling at all stations. More specifically, the cooling associated with these trends in SST is $-10,-3$, and $-4 \%$, respectively (Fig. 10b). The associated confidence limits are relatively wide and overlap extensively for all three stations, indicating that the differences in the slopes may not be statistically significant and that the differences with and without modes C5 and C6 may not be statistically significant.

In addition to regime shifts, ENSO events also affect marine ecosystem and fisheries in the EJS. Kim and Kang (2000) analyzed ecological variations due to El Niños off the south coast of Korea using the Southern Oscillation Index (SOI) and SST as indicators. The SOI and SST in December were highly correlated and the variability in anchovy and mackerel catch was associated with El Niño episodes because of changes in the ecosystems in December.

\section{DECADAL TIMESCALES}

Next we consider the SSTA variability in decadal time scales due to thermal advection in the EKWC resulting from sea level changes in the North Pacific through changes in the Kuroshio Current System. For the relations between SSTA off the east coast of Korea and the North Pacific current system, we consider the North Pacific Gyre Oscillation $(\mathrm{NPGO})^{2}$, which is a climate pattern that emerges as the second dominant mode of sea surface height variability in the Northeast Pacific (Di Lorenzo et al. 2008). Variations in the NPGO may reflect changes in the intensity of the North Pacific gyre circulation.

In order to examine the relation between the SSTA and NPGO, we performed a cross-correlation analysis and found that the lags vary from $4-7$ months. The maximum correlations between decadal SST signals and NPGO are 0.27 at $90 \%$ confidence level, 0.43 at $91 \%$ confidence level, and 0.36 at $92 \%$ confidence level for stations 3,6 , and 10 , respectively. The dominant peaks in the NPGO are approxi-

2 http://www.ocean3d.org/npgo mately 12 years apart (peaks at 1976, 1987, and 2000), with the major peaks in the SSTA being closely aligned, taking into account the lag relationship (Fig. 12). The peaks are most likely related to the decadal oscillations that are reflected in the NPGO index, which have often been observed and reported in the EJS (e.g., Gordon and Giulivi 2004). According to Gordon and Giulivi (2004), the sea surface height anomaly in the EJS is related with PDO changes through the geostrophic transport of the Kuroshio, which is weaker (stronger) during a negative (positive) PDO and thus water temperature in EJS is warmer during the negative PDO [their Figs. 4a and c in Gordon and Giulivi (2004)]. Our SSTA time series includes both the negative (before 1976) and the positive (after 1977) PDO phase, suggesting that the Tsushima Current transport which feeds the EJS and contributes to the SSTA increase in our study area.

From the EEMD analyses we see that mode C7 captures the time scales associated with decadal scale variations as shown in Figs. 4, 5, and 6 for stations 3, 6, and 10, respectively (Fig. 12). We then compared smoothed mode C7 from an EEMD analysis of the NPGO index time series with smoothed mode $\mathrm{C} 7$ for the three stations and found a high degree of similarity (Fig. 12). These quasi-decadal maxima in SSTA and the NPGO are also most likely related to the 10 - 15 year ENSO modulation cycle that has been identified and discussed in detail (or called El Niño Modoki) in recent years (e.g., Yeh and Kirtman 2005; Sun and Yu 2009). According to Di Lorenzo et al. (2008), the decadal dynamics of the PDO and the NPGO are linked through their relationship to ENSO events, and the second dominant NPGO mode (affected by the North Pacific Oscillation) is well captured from our decadal warming cycle. This indicates the extensive impacts of NPGO and its related circulation process.

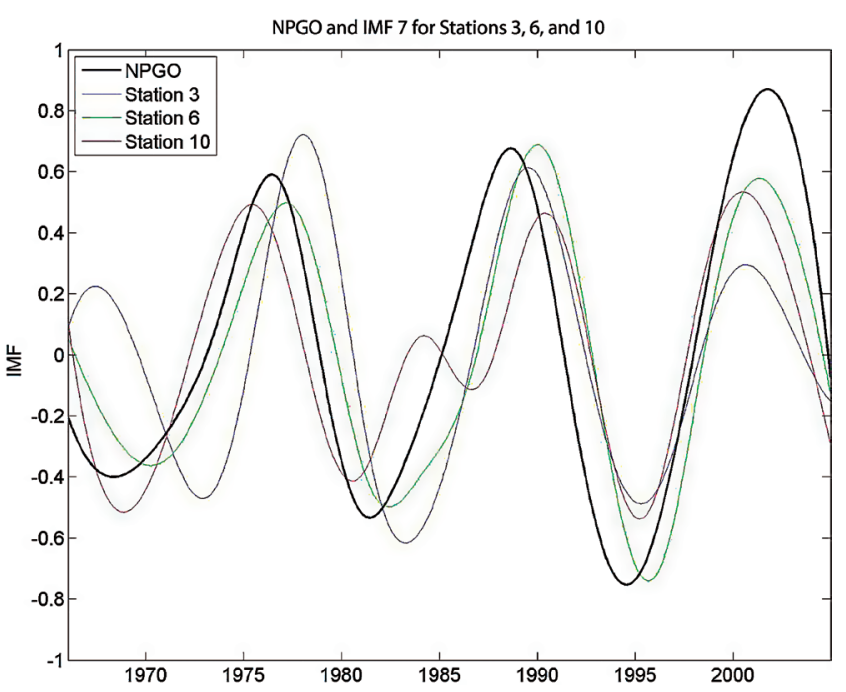

Fig. 12. Time series comparison between IMF 7 (C7) from an EEMD and the NPGO index at each station. 


\section{LONG-TERM WARMING TRENDS}

The impact of warming associated with the long-term trends from the residual mode $(\mathrm{R})$ of the EEMD decomposition is shown in Fig. 10a. The long-term trends for residual mode at each station clearly are the largest contributors to the warming process (Fig. 10b) after 1961. Their impacts are far greater than that from any of the lower modes. Figure 13 shows the linear trends, the LOESS smoothing and the residuals from the EEMD decomposition plotted together for each station. From the long-term trends (black) and the EEMD residuals (red), we see that SSTAs have increased by as much as $1.5^{\circ}-2.0^{\circ} \mathrm{C}$ from 1966 to 2004 and that the rate

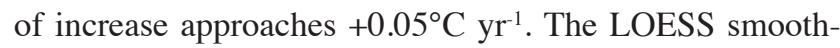

ing in addition shows the previously discussed major peaks in the mid-1970's, circa 1990 and circa 2000, that are superimposed on the long-term warming trends. The warming trends are similar at each station suggesting that the process or processes responsible for this warming are not local in nature but most likely affect the entire region (e.g., Levitus et al. 2000, 2005).

\section{DISCUSSION}

Our results show that there are higher warming rates during the winter season 494 than summer for all three stations (Fig. 8). These seasonal changes are significant and 495 are consistent with the results of Ross et al. (1996),
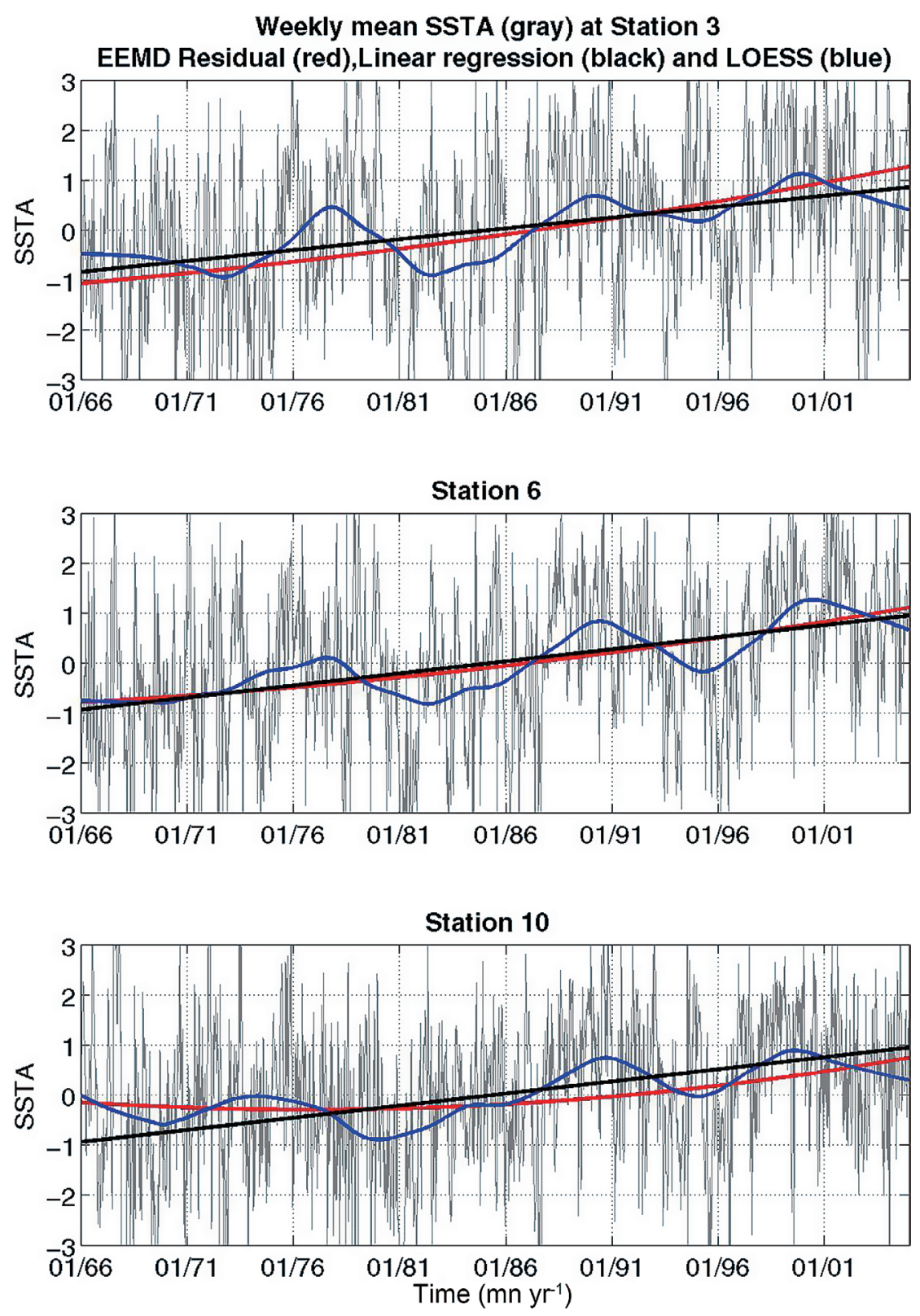

Fig. 13. Linear regression, residual, and LOESS on the weekly mean SSTA for stations 3, 6, and 10, respectively. 
who found warming over Siberia related to a weaker Siberian High $(\mathrm{SH})$ in winter leading to milder winters over the East Asia region including the waters off the east coast of South Korea. Youn (2005) showed that the SH air mass has warmed significantly during the winter period over the past several decades, which may be an important contributing factor to the seasonal warming that we have observed along the coast of South Korea. According to two studies (Ross et al. 1996; Youn 2005), a relationship exists between the weakening in the $\mathrm{SH}$ and decreasing northerly winds during the winter, resulting in warming air temperatures as much as $+1.5^{\circ} \mathrm{C}$ for 100 years around the Korean peninsula. This study also points out that the spectra for the warming signals reveal interannual and decadal variability, although the temperature data cannot be directly linked to ENSO influence.

The influence of interannual ENSO events on the SSTA along the Korean coast is examined. After extracting ENSO events from the SSTAs, our results show that while SST increased at station $3(+14 \%)$, SST decreased at stations $6(-26 \%)$ and $10(-30 \%)$ (Fig. 10b). The reason for the differences between stations is as follows. Extreme phases of ENSO events modulate the general circulation in the marginal sea through global air-sea interactions (Park and Oh 2000). Since SST is primarily determined by these circulation systems, different aspects of ENSO influence arise from the subpolar front associated with the general circulation pattern in the region. The subpolar front is zonal in orientation and crosses the EJS at about $37^{\circ}-39^{\circ} \mathrm{N}$ (Fig. 1). This front divides the sea into subtropical and subpolar regimes. While the subtropical circulation, south of the subpolar front, is somewhat anticyclonic, the subpolar circulation, north of the subpolar front, is cyclonic. As a result, stations 6 and 10 are under the influence of the subtropical circulation and the EKWC, while station 3 is primarily under the influence of the subpolar circulation and the NKCC.

The monthly mean NPGO, and EEMD C7 all reveal decadal scale variations, which contribute significantly to the warming process (Fig. 12) (section 8). Since the NPGO is locally forced by surface wind variability associated with the North Pacific Oscillation (NPO), it can be seen as the oceanic expression of NPO, which characterizes the high sea level pressure over Hawaii and low pressure in the Gulf of Alaska. The oceanic sea level anomalies forced by the NPO could trigger oceanic adjustment through westward propagating Rossby waves, which can reach the North Pacific western boundary and modulate the decadal variation of the Kuroshio Current System (Tseng et al. 2012). Thus, the results in the observed decadal signals in this study link to the Kuroshio.

Recent studies also suggest that the warming trends in the Yellow/East China Sea and the EJS are associated changes in wind patterns resulting from the NPO during winter (Yeh and Kim 2010; Yeh et al. 2010). The studies claim that NPO-like sea level pressure over the North Pacific causes a weakening in the northerly mean winds over the seas during winter, which contributes to increase the SST. Because the NPGO and wind patterns are directly related, we interpret their mechanism as that surface warm waters are advected from the North Pacific to the EJS in response to NPGO.

These results are also consistent with the possible precursor signals found prior to ENSO episodes (see section 7). Casey and Adamec (2002) studied the relationship between SST and SSH variability over the North Pacific and showed that some of the Kuroshio transport-related changes are due to variations in the subtropical Pacific SSH. Han and Kang (2003) estimated how much heat is transported into the EJS through the Korea Strait. Using historical surface current data from 1999 - 1993 (Japan Oceanographic Data Center), they estimated heat supplied by the current (HSC) in the EJS. The results showed that heat transport associated with the HSC was large in the northwest EJS and small in the southeast EJS, suggesting that the warm current is restricted primarily to the surface layer around the northeast EJS, and extends deeper in the southeast EJS. Gordon and Giulivi (2004) illustrate that the recent warming SST is related with the positive PDO phase, resulting in enhancing Tsushima Current from the North Pacific Ocean. Thus, heat transport from the north Pacific may be a significant factor that contributes to the thermal regime in the EJS on decadal timescales.

Thus, our results are consistent with the large changes in heat content observed in other Asian marginal seas through transport by advection (Tseng et al. 2010). These largescale decadal variations may be an extension of the larger trend in ocean heat content in the Western Pacific shown in earlier studies (Levitus et al. 2005; Ishii et al. 2006; Tseng et al. 2010), reflecting the regional response to interannual/ decadal climate variability. This argument is supported by the consistency and high correlation with 4 - 7 month lags between the SSTA and the NPGO, which is not surprising and reflects the advection speeds $(\mathrm{V}=\mathrm{L} / \mathrm{T})$ associated with the basin-scale current transport (e.g., through the Korean Strait in Fig. 1) as discussed in section 8. L is distance from $20^{\circ}$ north-west Pacific to station 10 of our study area, which is approximately $24418 \mathrm{~km}$. $\mathrm{T}$ is the lags, $4-7$ months. Thus, advection speeds are approximately $23.2 \mathrm{~cm} \mathrm{~s}^{-1}$ with 4 months lag and $13.2 \mathrm{~cm} \mathrm{~s}^{-1}$ with 7 months lag.

\section{SUMMARY AND CONCLUSIONS}

A number of conclusions can be drawn from this study. First, sea surface temperatures increase more in winter than in the summer season resulting from the recently weakened $\mathrm{Si}$ berian High. Second, the influence of ENSO events on cooling trends depends on the location along the coast of Korea. The reasons are as follows. stations 3, 6, and 10 are directly exposed to the influence of the NKCC and EKWC coastal currents and not to the open waters of the EJS. Figure 1 shows that the circulation off the coast of South Korea is 
quite distinct from the circulation further offshore in the EJS. Consequently, it is not surprising and perhaps to be expected, that our results differ from those of Hong et al. (2001).

However, these results do show what might be called pre-cursors to the major El Niño episodes (e.g., the 1982 - 1983 event). That we observe "pre-cursor" events, i.e., relatively large decreases in temperature, prior to the major El Niño's since 1980 may be significant and potentially useful in a predictive sense. These cooling events before major ENSOs are frequently observed in western Pacific prior to El Niño events (e.g., Wang et al. 2012) and could result in the recognized "Seasonal Footprinting Mechanism" (SFM) at mid-latitudes (Vimont et al. 2003). The SFM suggests that Northern Hemisphere wintertime sea level pressure variability over the extra tropics initiates an SST footprint onto the ocean via changes in the net surface heat flux. The North Pacific Oscillation (NPO), like sea level pressure patterns, may be related to the cool pre-cursor events observed in the EJS. Further study is required to investigate the pre-cursor mechanisms in the Western Pacific and how they initiate SFM.

This may be traced to different water masses that are separated by the subarctic front (station 3 ) and the subtropical front (stations 6 and 10). Third, the decadal warming off the coast of Korea is related to warm water that is advected from the Northwest Pacific as illustrated through the NPGO, suggesting that the EJS is an important part of West Pacific circulation. Finally, according to our observed longterm warming trends, they are significantly larger than the global warming trend reported by the IPCC. The impact of global warming on the marginal seas is also reported by Belkin (2009, his Table 1). Although the SST trends estimated by the IPCC and our SST data are not based on the same ground, there are significant warming trends in the marginal seas. SST in this case has increased by up to eight times the global average $\left(\sim+0.041^{\circ} \mathrm{C} \mathrm{yr}^{-1}\right.$ versus $\left.\sim+0.005^{\circ} \mathrm{C} \mathrm{yr} r^{-1}\right)$.

Sea surface warming through long-term atmospheric changes should also be considered in the study area. This study is focused mainly on the variability in multi-temporal SSTA scales off the east coast of Korea in response to changes in the North Pacific Ocean. With the benefit of a numerical model we may address and quantify atmospheric and/or oceanic contributions to the warming/cooling of sea surface waters in different time scales.

Acknowledgements The authors are grateful to the anonymous Reviewers for their valuable comments and suggestions on this manuscript and for their encouragement. This study was supported by the Research Fund Program of Research Institute for Basic Sciences, Pusan National University, Korea, 2013, Project No. RIBS-PNU-2013-xxx. S.W. Yeh was funded by the Korea Meteorological Administration Research and Development Program under Grant CATER 2012-3041.

\section{REFERENCES}

An, J. B. and H. S. Park, 1996: An atmospheric response to SST anomaly in the tropical Pacific using GCM with OSU two-layer. J. Korean Meteorol. Soc., 32, 389-399.

Bakun, A., 2004: Regime shifts. In: Robinson, A. R., J. McCarthy, and B. J. Rothchild (Eds.), The Sea 13, Wiley, New York, 971-1018.

Balling, R. C. Jr, P. J. Michaels, and P. C. Knappenberger, 1988: Analysis of winter and summer warming rates in gridded temperature time series. Clim. Res., 9, 175181, doi: 10.3354/cr009175. [Link]

Belkin, I. M., 2009: Rapid warming of large marine ecosystems. Prog. Oceanogr., 81, 207-213, doi: 10.1016/j. pocean.2009.04.011. [Link]

Breaker, L. C., 2007: A closer look at regime shifts based on coastal observations along the eastern boundary of the North Pacific. Cont. Shelf Res., 27, 2250-2277, doi: 10.1016/j.csr.2007.05.018. [Link]

Breaker, L. C. and S. J. Flora, 2009: Expressions of 19761977 and 1988-1989 regime shifts in sea-surface temperature off southern California and Hawai'i. Pacific Sci., 63, 39-60.

Casey, K. S. and D. Adamec, 2002: Sea surface temperature and sea surface height variability in the North Pacific Ocean from 1993 to 1999. J. Geophys. Res., 107, 14-114-12, doi: 10.1029/2001JC001060. [Link]

Chu, P. C., Y. Chen, and S. Lu, 1998: Temporal and spatial variabilities of Japan Sea surface temperature and atmospheric forcings. J. Oceanogr., 54, 273-284, doi: 10.1007/BF02751702. [Link]

Cleveland, W. S., 1979: Robust locally weighted regression and smoothing scatterplots. J. AM. Stat. Assoc., 74, 829836, doi: 10.1080/01621459.1979.10481038. [Link]

Di Lorenzo, E., N. Schneider, K. M. Cobb, P. J. S. Franks, K. Chhak, A. J. Miller, J. C. McWilliams, S. J. Bograd, H. Arango, E. Curchitser, T. M. Powell, and P. Rivière, 2008: North Pacific Gyre Oscillation links ocean climate and ecosystem change. Geophys. Res. Lett., 35, L08607, doi: 10.1029/2007GL032838. [Link]

Dorman, C. E., R. C., Beardsley, R. Limeburner, S. M. Varlamov, M. Caruso, and N. A. Dashko, 2005: Summer atmospheric conditions over the Japan/East Sea. DeepSea Res. Part II-Top. Stud. Oceanogr., 52, 1393-1420, doi: 10.1016/j.dsr2.2004.09.033. [Link]

Emery, W. J. and R. E. Thomson, 1997: Data Analysis Methods in Physical Oceanography, Pergamon Press, New York , 634 pp.

Gordon, A. L. and C. F. Giulivi, 2004: Pacific decadal oscillation and sea level in the Japan/East sea. Deep-Sea Res. Part I-Oceanogr. Res. Pap., 51, 653-663, doi: 10.1016/j.dsr.2004.02.005. [Link]

Han, I. S. and Y. Q. Kang, 2003: Supply of heat by Tsushima Warm Current in the East Sea (Japan Sea). J. Oceanogr., 
59, 317-323, doi: 10.1023/A:1025563810201. [Link]

Hawkins, D. M. and D. H. Olwell, 1998: Cumulative Sum Charts and Charting for Quality Improvement, Information Science and Statistics, Springer, New York, $247 \mathrm{pp}$.

Hong, C. H., K. D. Cho, and H. J. Kim, 2001: The relationship between ENSO events and sea surface temperature in the East (Japan) Sea. Prog. Oceanogr., 49, 2140, doi: 10.1016/S0079-6611(01)00014-3. [Link]

Huang, N. E., 2005a: Introduction to Hilbert-Huang Transform and some recent developments. In: Huang, N. E. and N. O. Attoh-Okine (Eds.), The Hilbert-Huang Transform in Engineering, Taylor \& Francis Group, LLC, Boca Raton, 1-23, doi: 10.1201/9781420027532. ch1. [Link]

Huang, N. E., 2005b: Introduction to the Hilbert-Huang Transform and its related mathematical problems. In: Huang, N. E. and S. S. P Shen (Eds.), Hilbert-Huang Transform and its Applications, Interdisciplinary Mathematical Sciences, Vol. 5, World Scientific, New Jersey, 1-26.

Huang, N. E., Z. Shen, S. R. Long, M. C. Wu, H. H. Shih, Q. Zheng, N. C. Yen, C. C. Tung, and H. H. Liu, 1998: The empirical mode decomposition and the Hilbert spectrum for nonlinear and non-stationary time series analysis. Proc. R. Soc. Lond. A, 454, 903-995, doi: 10.1098/rspa.1998.0193. [Link]

Huntsberger, D. V., 1965: Elements of Statistical Inference, Allyn and Bacon, Boston, 291 pp.

Intergovernmental Panel on Climate Change (IPCC), 2007: Summary for Policymakers. In: Solomon, S., D. Qin, M. Manning, Z. Chen, M. Marquis, K. B. Averyt, M. Tignor, and H. L. Miller (Eds.), Climate Change 2007: The Physical Science Basis, Contribution of Working Group I to the Fourth Assessment Report of the Intergovernmental Panel on Climate Change, Cambridge University Press, Cambridge, United Kingdom and New York, USA, 996 pp.

Ishii, M., M. Kimoto, K. Sakamoto, and S. I. Iwasaki, 2006: Steric sea level changes estimated from historical ocean subsurface temperature and salinity analyses. J. Oceanogr., 62, 155-170, doi: 10.1007/s10872-0060041-y. [Link]

Kang, S. K., J. Y. Cherniawsky, M. G. G. Foreman, H. S. Min, C. H. Kim, and H. W. Kang, 2005: Patterns of recent sea level rise in the East/Japan Sea from satellite altimetry and in situ data. J. Geophys. Res., 110, C07002, doi: 10.1029/2004JC002565. [Link]

Kang, I. S. and H. J. Bak, 1993: A long-term prediction of monthly mean air temperature in Korea during winter. J. Korean Meteorol. Soc., 29, 253-262.

Kidokoro, H., T. Goto, T. Nagasawa, H. Nishida, T. Akamine, and Y. Sakurai, 2010: Impact of a climate regime shift on the migration of Japanese common squid (Todarodes pacificus) in the Sea of Japan. ICES J. Mar. Sci., 67, 1314-1322, doi: 10.1093/icesjms/ fsq043. [Link]

Kim, S. and S. Kang, 2000: Ecological variations and El Niño effects off the southern coast of the Korean Peninsula during the last three decades. Fish. Oceanogr., 9, 239247, doi: 10.1046/j.1365-2419.2000.00142.x. [Link]

Lee, J. C.,1983: Variations of sea level and sea surface temperaure associated with wind-induced upwelling in the southeast coast of Korea in summer. J. Oceanogr. Soc. Korea, 18, 149-160.

Lee, K. B., 1978: Study on the coastal cold water near Ulsan. J. Oceanogr. Soc. Korea, 13, 5-10.

Lee, D. K. and P. P. Niiler, 2005: The energetic surface circulation patterns of the Japan/East Sea. Deep-Sea Res. Part II-Top. Stud. Oceanogr., 52, 1547-1563, doi: 10.1016/j.dsr2.2003.08.008. [Link]

Levitus, S., J. I. Antonov, T. P. Boyer, and C. Stephens, 2000: Warming of the world ocean. Science, 287, 22252229, doi: 10.1126/science.287.5461.2225. [Link]

Levitus, S., J. I. Antonov, and T. P. Boyer, 2005: Warming of the world ocean, 1955-2003. Geophys. Res. Lett., 32, L02604, doi: 10.1029/2004GL021592. [Link]

Min, H. S. and C. H. Kim, 2006: Water mass formation variability in the intermediate layer of the East Sea. Ocean. Sci. J., 41, 255-260, doi: 10.1007/BF03020629. [Link]

Minami, H., Y. Kano, and K. Ogawa, 1999: Long-term variations of potential temperature and dissolved oxygen of the Japan Sea Proper Water. J. Oceanogr., 55, 197205, doi: 10.1023/A:1007889929187. [Link]

Oh, J. S., 1996: A study of Asian Monsson in summer during El Niño in 1987 and La Nina in 1988 using METRI/ YONU GCM. J. Korean Meteorol. Soc., 32, 111-129.

Page,E.S.,1954: Continuous inspection schemes. Biometrika, 41, 100-115, doi: 10.1093/biomet/41.1-2.100. [Link]

Park, S. and P. C. Chu, 2006: Interannual SST variability in the Japan/East Sea and relationship with environmental variables. J. Oceanogr., 62, 115-132, doi: 10.1007/ s10872-006-0038-6. [Link]

Park, W. S. and I. S. Oh, 2000: Interannual and interdecadal variations of sea surface temperature in the East Asian Marginal Seas. Prog. Oceanogr., 47, 191-204, doi: 10.1016/S0079-6611(00)00036-7. [Link]

Pratt, W. K., 1978: Digital Image Processing, Wiley, 750 pp.

Ross, R. J., J. Otterman, D. O'C. Starr, W. P. Elliott, J. K. Angell, and J. Susskind, 1996: Regional trends of surface and tropospheric temperature and eveningmorning temperature difference in northern latitudes: 1973-93. Geophys. Res. Lett., 23, 3179-3182, doi: 10.1029/96GL03076. [Link]

Seung, Y, H., 1992: A simple model for separation of East Korean Warm Current and formation of North Korean Cold Current. J. Oceanogr. Soc. Korea, 27, 189-196.

Seung, Y. H. and K. Kim, 1989: On the possible role of 
local thermal forcing on the Japan Sea circulation. $J$. Oceanogr. Soc. Korea, 24, 29-38.

Sun, F. and J. Y. Yu, 2009: A 10-15-yr modulation cycle of ENSO intensity. J. Climate, 22, 1718-1735, doi: 10.1175/2008JCLI2285.1. [Link]

Talley, L. D., D. H. Min, V. B. Lobanov, V. A. Luchin, V. I. Ponomarev, A. N. Salyuk, A. Y. Shcherbina, P. Y. Tishchenko, and I. Zhabin, 2006: Japan/East Sea water masses and their relation to the sea's circulation. Oceanography, 19, 32-49, doi: 10.5670/oceanog.2006.42. [Link]

Teague, W. J., G. A. Jacobs, H. T. Perkins, J. W. Book, K. I. Chang, and M. S. Suk, 2002: Low-frequency current observations in the Korea/Tsushima Strait. J. Phys. Oceanogr., 32, 1621-1641, doi: 10.1175/1520-0485(2002)032<1621:LFCOIT>2.0.CO;2. [Link]

Tian, Y., K. Nashida, and H. Sakaji, 2013: Synchrony in the abundance trend of spear squid Loligo bleekeri in the Japan Sea and the Pacific Ocean with special reference to the latitudinal differences in response to the climate regime shift. ICES J. Mar. Sci., 70, 968-979, doi: 10.1093/icesjms/fst015. [Link]

Tseng, Y. H., L. C. Breaker, and E. T. Y. Chang, 2010: Sea level variations in the regional seas around Taiwan. $J$. Oceanogr., 66, 27-39, doi: 10.1007/s10872-010-00032. [Link]

Tseng, Y. H., M. L. Shen, S. Jan, D. E. Dietrich, and C. P. Chiang, 2012: Validation of the Kuroshio Current System in the dual-domain Pacific Ocean Model framework. Prog. Oceanogr., 105, 102-124, doi: 10.1016/j. pocean.2012.04.003. [Link]

Vimont, D. J., J. M. Wallace, and D. S. Battisti, 2003: The seasonalfootprinting mechanism in the Pacific: Implications forENSO.J.Climate, 16,2668-2675, doi: 10.1175/15200442(2003)016<2668:TSFMIT>2.0.CO;2. [Link]

Wang, S. Y., M. L'Heureux, and H. H. Chia, 2012: ENSO prediction one year in advance using western North $\mathrm{Pa}$ cific sea surface temperatures. Geophys. Res. Lett., 39, L05702, doi: 10.1029/2012GL050909. [Link]

Wetherill, G. B. and D. W. Brown, 1991: Statistical Process Control: Theory and Practice, Chapman and Hall, London, $400 \mathrm{pp}$.

Wu, Z. and N. E. Huang, 2005: Statistical significance test of intrinsic mode functions. In: Huang, N. E. and S. S. P. Shen (Eds.), Hilbert-Huang Transform and its Applications, Interdisciplinary Mathematical Sciences, Vol. 5, chapter 5, 311 .

Wu, Z. and N. E. Huang, 2009: Ensemble Empirical Mode Decomposition: A noise-assisted data analysis method. Adv. Adapt. Data Anal., 1, 1-41, doi: 10.1142/ S1793536909000047. [Link]

Yasunari, T., 1990: Impact of Indian monsoon on the coupled atmosphere/ocean system in the tropical pacific. Meteorol. Atmos. Phys., 44, 29-41, doi: 10.1007/
BF01026809. [Link]

Yeh, S. W. and C. H. Kim, 2010: Recent warming in the Yellow/East China Sea during winter and the associated atmospheric circulation. Cont. Shelf Res., 30, 14281434, doi: 10.1016/j.csr.2010.05.002. [Link]

Yeh, S. W. and B.P. Kirtman, 2005: Pacific decadal variability and decadal ENSO amplitude modulation. Geophys. Res. Lett., 32, L05703, doi: 10.1029/2004GL021731. [Link]

Yeh, S. W., Y. G. Park, H. S. Min, C. H. Kim, and J. H. Lee, 2010: Analysis of characteristics in the sea surface temperature variability in the East/Japan Sea. Prog Oceanogr., 85, 213-223, doi: 10.1016/j.pocean.2010.03.001. [Link]

Yoon, J. H., 1982: Numerical experiment on the circulation in the Japan Sea. Part III. Mechanism of the nearshore branch of the Tsushima Current. J. Oceanogr. Soc. Japan, 38, 125-130, doi: 10.1007/BF02110283. [Link]

Youn, Y. H., 2005: The climate variabilities of air temperature around the Korean Peninsula. Adv. Atmos. Sci., 22, 575-584, doi: 10.1007/BF02918489. [Link]

Zhang, C. I., J. B. Lee, S. Kim, and J. H. Oh, 2000: Climatic regime shifts and their impacts on marine ecosystem and fisheries resources in Korean waters. Prog. Oceanogr., 47, 171-190, doi: 10.1016/S0079-6611(00)00035-5. [Link]

Zhang, C. I., S. C. Yoon, and J. B. Lee, 2007: Effects of the 1988/89 climatic regime shift on the structure and function of the southwestern Japan/East Sea ecosystem. J. Mar. Syst., 67, 225-235, doi: 10.1016/j.jmarsys.2006.05.015. [Link]

\section{APPENDIX}

Hilbert Spectral Analysis/Empirical Mode Decomposition (HSA/EMD) is a relatively new empirical technique for analyzing non-stationary and nonlinear time series that includes HSA and EMD. This method was introduced by Huang et al. (1998), and further described in Huang (2005a, b). Based on EMD, the data are initially decomposed into a set of Intrinsic Mode Function (IMF) components. Local maxima and minima are identified in the record and envelopes are formed by fitting cubic splines to the extreme values. The differences between the envelope and the mean provide an estimate of the first IMF component. These steps are repeated to obtain improved estimates of the first IMF. The process, called sifting, extracts the essential scales from the data. According to Huang et al. (1998), an IMF represents a simple oscillatory mode, and, in general, has variable amplitude and frequency expressed as functions of time.

Once the first IMF, $\operatorname{im} f_{1}$, has been obtained, based on the stopping criterion adopted, it is subtracted from the original data, $x(t)$, producing a set of residuals, $r_{1}$, which can be expressed as 


$$
x(t)-i m f_{1}=r_{1}
$$

The residuals, $r_{1}$, are then subjected to the same process, yielding the second IMF, $\operatorname{imf}_{2}$, as

$r_{2}=r_{1}-i m f_{2}$

and so on, until a final residual is obtained that often corresponds to a long-term trend in the data. Because the IMF components are essentially independent and thus can be linearly combined, we can reconstruct the original record, $x(t)$, according to

$x(t)=\sum_{i=1}^{n} i m f_{i}+r_{n}$

where $n$ represents the total number of IMFs. According to Huang (2005a), the IMF components are often physically meaningful and so can provide insight into the processes involved.

One of the major problems with conventional EMD is the frequent appearance of mode mixing which can produce signals of disparate scales residing in the same IMF component. In order to overcome this problem, Wu and Huang (2009) introduced a newer version of EMD called Ensemble Empirical Mode Decomposition (EEMD) that produces improved IMF components calculated as the mean of an ensemble of trials, each consisting of the signal plus white noise of finite amplitude. The $i^{\text {th }}$ realization of the simulated observations can be expressed as

$x_{i}(t)=x(t)+w_{i}(t)$

where, $x(t)$ is the original signal, i.e., imf, $w_{i}(t)$ represents the $i^{\text {th }}$ realization of the white noise process, and $x_{i}(t)$ is their sum. Extensive testing has shown that the quality of the decompositions is improved using this approach $(\mathrm{Wu}$ and Huang 2009). 